\title{
Optimal Design of Viscoelastic Dampers in Frame Structures considering Soil-Structure Interaction Effect
}

\author{
Xuefei Zhao, Shuguang Wang, Dongsheng Du, and Weiqing Liu \\ College of Civil Engineering, Nanjing Tech University, Nanjing 210009, China \\ Correspondence should be addressed to Shuguang Wang; 720108@vip.sina.com
}

Received 6 May 2016; Accepted 26 September 2016; Published 5 January 2017

Academic Editor: Giuseppe C. Marano

Copyright ( 2017 Xuefei Zhao et al. This is an open access article distributed under the Creative Commons Attribution License, which permits unrestricted use, distribution, and reproduction in any medium, provided the original work is properly cited.

\begin{abstract}
The seismic response control of multistory frame structures using optimally placed viscoelastic dampers (VEDs) within consideration of soil-structure interaction (SSI) effect is investigated in this paper. The system is assumed to be elastic and responses of the system are obtained in frequency domain for stationary random seismic excitations. The optimal designs of VEDs in structures are achieved through genetic algorithm (GA) by minimizing the maximum response quantities of the system for a determined total amount of viscoelastic material. Two typical elastic multistory frame structures with different soil types and foundation embedment ratios are considered to demonstrate the optimization process. It is shown that the VEDs have the best control of the structural response for fixed base condition and the control efficiency decreases as the soil becomes softer. The optimal placement types of VEDs for different soil types differ from each other. With the decrease of soil stiffness, the optimal locations of VEDs have a tendency to shift to top floors.
\end{abstract}

\section{Introduction}

In order to attain a high level of structural vibration control, various types of energy dissipation devices such as viscoelastic dampers (VEDs), viscous fluid dampers, and friction dampers have received considerable attention in recent years. Among the available devices, the VED has been successfully used in several buildings for the effective reduction of wind or earthquake induced vibrations.

The properties of VED, such as the behavior of energy dissipation mechanism or the dynamic stiffness, are frequency and temperature dependent, which are commonly defined in terms of experimentally obtained storage and loss modules. A more in-depth understanding of the dynamic behavior is required for the vibration analysis of structures supplemented with VEDs. In the past, several rheological models were proposed to describe the dynamic behavior of VEDs, such as the classical Maxwell model, Kelvin model, and the fractional-derivative model. These models are presented by Chang [1], Lewandowski [2], and other researchers.

The dynamic analyses of structures equipped with VEDs are presented in many papers; both analytical and experimental studies have shown that a significant reduction in structural response excited by earthquake motions can be achieved by adding VEDs to the structure. Zhang and Soong [3], Chang and Lin [4], and Hwang et al. [5] have reported that the VEDs can greatly reduce the seismic induced structural vibrations through the numerical examples. Researches by Tsai and Lee [6] and Lai et al. [7] have shown that VEDs are suitable for seismic mitigation of buildings. Extensive shaking table studies have revealed that the VEDs are very effective in reducing vibrations of structures due to mild and strong earthquakes for both steel and reinforced concrete structures at various environmental temperatures (Chang et al. [8] and Shen and Soong [9]).

Optimization analysis about structures with VEDs, including parameter and location optimization of VEDs in the structure, is an important problem from a practical point of view. In one case, the problem has been studied for idealized configuration of structures by Ashour [10]. A multistory building with identical properties at every story has been modeled as a uniform shear beam; optimal damper location is acquired to conform to the pattern of distribution that will result in maximizing the first mode damping ratio. 
A similar problem has been studied with regard to the active structural control by Chang and Soong; the optimal location of the dampers was obtained by minimizing a performance index of modal response [11]. Later, Zhang and Soong [3] extended the controllability index method to address the damper location problem, leading to a sequential procedure for the optimal placement of VEDs. Shukla and Datta [12] obtained the optimal locations of VEDs with the help of a controllability index, which is defined by the root-meansquare value of interstory drift.

Nevertheless, due to the complicated seismic analysis of structures considering soil-structure interaction (SSI) effect, most of the studies are carried out based on the assumption of rigid foundation. The researches conducted by Veletsos and Meek [13], Avilés and Pérez-Rocha [14], and Medina et al. [15] demonstrate that the SSI effect significantly modifies the structural dynamic characteristics and then influences the seismic response performance of the whole structure. Besides, the performance of VED is closely related to the dynamic characteristics of the structure, especially the structural frequencies, and thus it will be inevitably influenced by the SSI effect. Conversely, the stiffness and damping changes of the system induced by VEDs will affect the soilstructure interaction and vice versa. Accordingly, the seismic analysis of the soil-foundation-structure-damper system is a relatively complicated coupling problem. The assumption of rigid foundation may result in analytical inaccuracy and considerable deviation from the original design objective if the structures equipped with VEDs are located on relatively soft foundations. The optimal locations of VEDs in structures considering SSI effect may also be different from the optimization results based on rigid foundation assumptions. However, to the authors' knowledge, there are very few studies in scientific literatures focusing on the problem of optimal design of VEDs in structures considering the SSI effect.

The work in this paper is targeted at evaluating the SSI effect on the performance of VEDs and at finding the optimal placement of VEDs in the elastic frame structure. Because earthquakes are random phenomena, a stochastic procedure is used for evaluating the seismic response of the system. The free-field earthquake excitation is assumed to be stationary with mean value of zero and the effective input power spectral density function (PSDF) is obtained by modifying the free-field PSDF based on the kinematic interaction effect between soil and foundation. A genetic algorithm (GA) is used as a numerical searching technique to find the optimal locations of VEDs for a determined total amount of viscoelastic material. Finally, two typical earthquake excited elastic multistory frame structures with different foundation embedment ratios and soil types are considered to demonstrate the numerical optimal procedure.

\section{Simplified Model of Multistory Building with VEDs considering the SSI Effect}

Consider linear elastic $N$ degree-of-freedom frame structures containing VEDs supported by circular foundations

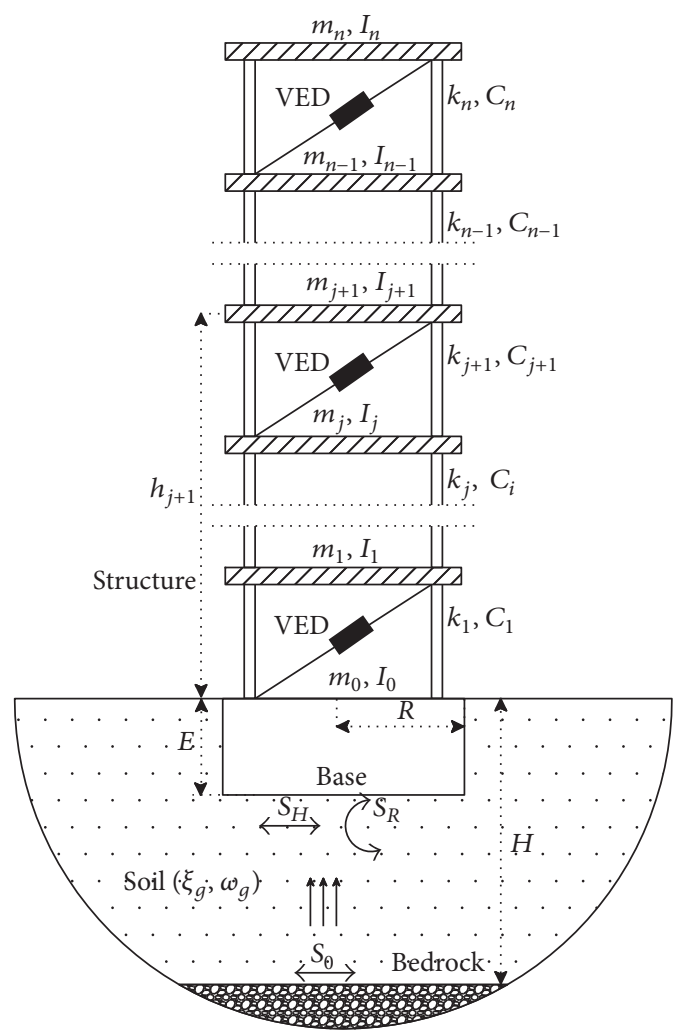

FIGURE 1: The model of frame structure with VEDs supported by embedment foundation.

embedded in the homogeneous viscoelastic and isotropic half-space as shown in Figure 1. The seismic response of the system can be studied using a substructure method, in which the model is subdivided into building-cap superstructure and soil-foundation system. According to Kausel and Roesset [16], the solution of the problem can be broken into three steps: the first step (kinematic interaction) is to determine the motion of massless foundation when subjected to the free-field motion; the next step is to determine the foundation impedance values, which are complex-valued frequency-dependent functions that represent the stiffness and damping of the soil in horizontal, rocking, and crosscoupled horizontal-rocking vibration, respectively; finally, the last step consists in the computation of the response at each frequency of the structure subjected to the motion computed in the first step.

2.1. Fractional-Derivative Maxwell Model for VED. The constitutive behavior of VED might be dependent upon the frequency, temperature, and amplitude. However, a mathematical model considering all these effects is very difficult to achieve. Therefore, for practical applications, isothermal conditions are usually considered in the simulation conditions. So, many mathematical constitutive models of VED just consider the frequency-dependent constitutive behavior. The five-parameter fractional-derivative Maxwell model (FDM) is used in this paper to demonstrate the general frequencydependent constitutive behavior of VED. The model was 
proposed by Makris and Constantinou [17] and validated by dynamic testing; very good agreement between the predicted and experimental results was obtained over a wide range frequency.

The linear dynamic properties of materials in the frequency domain are characterized by the complex modulus, and the relationship between force amplitude $\widehat{P}(\bar{\omega})$ and displacement amplitude $\widehat{u}(\bar{\omega})$ is as follows:

$$
\widehat{P}(\bar{\omega})=\left[G_{1}(\bar{\omega})+i G_{2}(\bar{\omega})\right] \widehat{u}(\bar{\omega}),
$$

where $G_{1}(\bar{\omega})$ and $G_{2}(\bar{\omega})$ are the frequency-dependent storage and loss stiffness of the damper, respectively, given as follows:

$$
\begin{aligned}
& G_{1}(\bar{\omega})=\frac{k_{0}\left[1+b_{0} \bar{\omega}^{\beta} \cos (\beta \pi / 2)\right]+c_{0} \bar{\omega}^{\alpha}\left[\cos (\alpha \pi / 2)+b_{0} \bar{\omega}^{\beta} \cos (((\alpha-\beta) / 2) \pi)\right]}{1+b_{0}{ }^{2} \bar{\omega}^{2 \beta}+2 b_{0} \bar{\omega}^{\beta} \cos (\beta \pi / 2)} \\
& G_{2}(\bar{\omega})=\frac{-b_{0} k_{0} \bar{\omega}^{\beta} \sin (\beta \pi / 2)+c_{0} \bar{\omega}^{\alpha}\left[\sin (\alpha \pi / 2)+b_{0} \bar{\omega}^{\beta} \sin (((\alpha-\beta) / 2) \pi)\right]}{1+b_{0}{ }^{2} \bar{\omega}^{2 \beta}+2 b_{0} \bar{\omega}^{\beta} \cos (\beta \pi / 2)} .
\end{aligned}
$$
tion:

The loss factor can be calculated by the following equa-

$$
\eta(\bar{\omega})=\frac{G_{2}(\bar{\omega})}{G_{1}(\bar{\omega})}
$$

The damping coefficient to a specific excitation frequency is defined as follows:

$$
c(\bar{\omega})=\frac{G_{2}(\bar{\omega})}{\bar{\omega}} .
$$

The undetermined parameters in (2) can be obtained by fitting the experimental results. A total of 26 tests were conducted by Makris and Constantinou [17] in the range of $0.01-50 \mathrm{~Hz}$ at a fixed room temperature (about $25^{\circ}$ ). Parameter $\alpha$ was set equal to unity, and parameters $b_{0}$ and $\beta$ were determined in a least-square fit of the elastic stiffness curve, which is defined as the square root of the sum of squares of storage and loss stiffness. Constant $c_{0}$ was then found by fitting the damping coefficient curve, which is described as (4). Finally, the obtained parameters are $k_{0}=$ $0 \mathrm{~N} / \mathrm{m}, c_{0}=15 \mathrm{kN} / \mathrm{m}, b_{0}=0.3 \mathrm{~s}^{0.6}, \alpha=1$, and $\beta=0.6$, and good agreement is achieved between the model and the test results. The frequency-dependent storage, loss stiffness, and damping coefficient are shown in Figure 2. The forcedisplacement loops for different excitation frequencies are shown in Figure 3.

The FDM has been widely used in engineering. Sun and Chen [18] have used the above parameters for the parametric study of free vibration of a taut cable with general viscoelastic dampers by altering $c_{0}$ while keeping other parameters constant. The FDM can also be applied to simulate the constitutive relation of other viscoelastic dampers such as Taylor devices, Jarett dampers, and HF2V dampers by fitting the five undetermined parameters through the experiment data in practical engineering.

2.2. Equilibrium Equations of the System. If the superstructure is equipped with only one VED denoted as the damper number $i$, which is mounted between two successive stories $j$ and $j+1$, then the force interaction vector $\mathbf{F}(t)$ could be written in the following form:

$$
\begin{aligned}
\mathbf{F}(t) & =\mathbf{F}_{i}(t)=\left[0, \ldots, F_{j}=f_{i}, F_{j+1}=-f_{i}, \ldots, 0\right]^{T} \\
& =\mathbf{L}_{i}^{T} f_{i}(t),
\end{aligned}
$$

where $\mathbf{L}_{i}=\left[0, \ldots, L_{i}=1, L_{i+1}=-1, \ldots, 0\right]$ is the $i$ th damper allocation vector of dimension $N \times 1$ and $f_{i}(t)$ is the damper force in time domain.

For a structure with $m$ dampers, the force interaction vector is given as follows:

$$
\mathbf{F}(t)=\sum_{i=1}^{m} \mathbf{F}_{i}(t)=\sum_{i=1}^{m} \mathbf{L}_{i}^{T} f_{i}(t) .
$$

Equation (6) can be written in frequency domain by Fourier transformation:

$$
\begin{aligned}
\mathbf{F}(\bar{\omega}) & =\sum_{i=1}^{m} \mathbf{F}_{i}(\bar{\omega})=\sum_{i=1}^{m} \mathbf{L}_{i}^{T} f(\bar{\omega}) \\
& =\sum_{i=1}^{m} \mathbf{L}_{i}^{T}\left[G_{1}(\bar{\omega})+i G_{2}(\bar{\omega})\right] \cos ^{2} \theta_{0} \mathbf{L}_{i} \mathbf{u}(\bar{\omega})
\end{aligned}
$$

where $\mathbf{u}(\bar{\omega})$ represents the Fourier transform of the structural displacement and $\theta_{0}$ represents the installation angle of the VED.

The governing equations of motion in the frequency domain for the case where soil and structure behave linearly are given as follows:

$$
\begin{aligned}
& \left\{-\bar{\omega}^{2}[\mathbf{M}]+j \bar{\omega}[\mathbf{C}]+[\mathbf{K}]\right\} \mathbf{U}(\bar{\omega}) \\
& \quad=-[\mathbf{M}]\left\{\boldsymbol{\Gamma} \cdot H_{u}(\bar{\omega})+\boldsymbol{\gamma} \cdot H_{\phi}(\bar{\omega})\right\} \ddot{U}_{g}(\bar{\omega}),
\end{aligned}
$$

where $\mathbf{U}(\omega)=\left\{\mathbf{u}(\bar{\omega}), u_{0}(\bar{\omega}), \phi_{0}(\bar{\omega})\right\}^{T}$ is the displacement vector of the system that consists of the structural displacement $\mathbf{u}(\bar{\omega})$ and the translation and rocking motions of the foundation $u_{0}(\bar{\omega})$ and $\phi_{0}(\bar{\omega})$; the symbol $j=\sqrt{-1}$ and $\bar{\omega}$ indicates the excitation frequency; $\ddot{U}_{g}(\bar{\omega})$ represents the free-field ground 


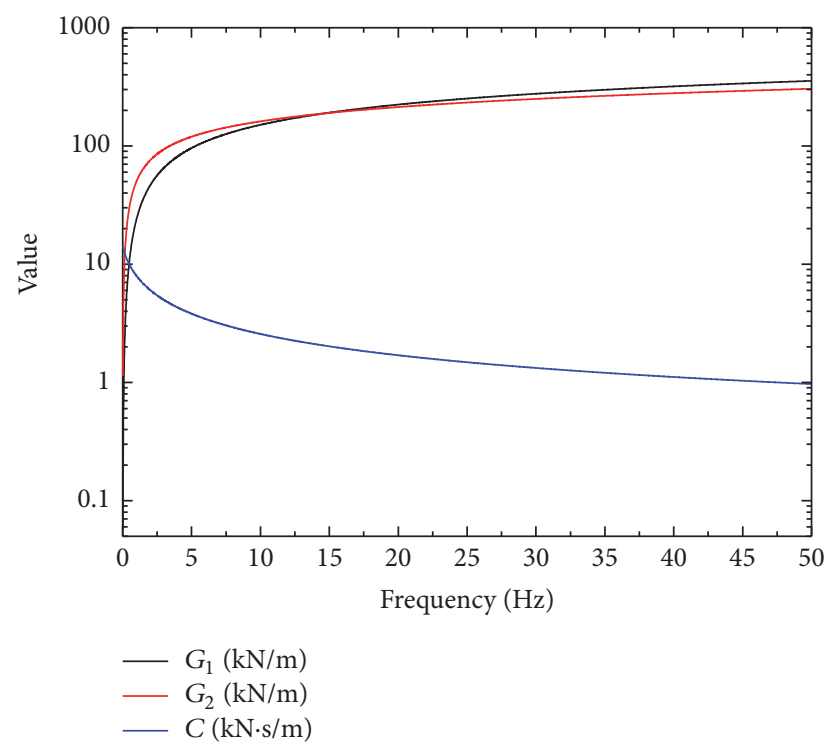

Figure 2: Stiffness and damping coefficient of the FDM.

motion. The general mass, stiffness, and damping matrices $[\mathbf{M}],[\mathbf{K}]$, and $[\mathbf{C}]$ in (8) are given by

$$
\begin{aligned}
& {[\mathbf{M}]=\left(\begin{array}{ccc}
\mathbf{M}_{s} & \mathbf{M}_{s} \psi & \mathbf{M}_{s} \boldsymbol{\Lambda} \\
\boldsymbol{\psi}^{T} \mathbf{M}_{s} & M_{T} & E_{T} \\
\boldsymbol{\Lambda}^{T} \mathbf{M}_{s} & E_{T} & I_{T}
\end{array}\right),} \\
& {[\mathbf{K}]=\left(\begin{array}{ccc}
\mathbf{K}_{s}+\mathbf{K}_{d} & 0 & 0 \\
0 & K_{h h} & K_{h r} \\
0 & K_{r h} & K_{r r}
\end{array}\right),} \\
& {[\mathbf{C}]=\left(\begin{array}{ccc}
\mathbf{C}_{s}+\mathbf{C}_{d} & 0 & 0 \\
0 & C_{h h} & C_{h r} \\
0 & C_{r h} & C_{r r}
\end{array}\right),}
\end{aligned}
$$

where

$$
\begin{aligned}
E_{T} & =m_{0} \frac{E}{2}+\sum_{i=1}^{n} \mathbf{M}_{s}(i, i) \cdot \Lambda(i) \\
M_{T} & =m_{0}+\sum_{i=1}^{n} \mathbf{M}_{s}(i, i) \\
I_{T} & =m_{0}\left(\frac{E}{2}\right)^{2}+I_{0}+\sum_{i=1}^{n}\left[\mathbf{M}_{s}(i, i) \cdot \Lambda^{2}(i)+I_{i}\right] \\
\mathbf{K}_{d}(\bar{\omega}) & =\sum_{i=1}^{m} \mathbf{L}_{i}{ }^{T} G_{1}(\bar{\omega}) \cos ^{2} \theta_{0} \mathbf{L}_{i} \\
\mathbf{C}_{d}(\bar{\omega}) & =\sum_{i=1}^{m} \mathbf{L}_{i}{ }^{T} \frac{G_{2}(\bar{\omega})}{\bar{\omega}} \cos ^{2} \theta_{0} \mathbf{L}_{i}
\end{aligned}
$$

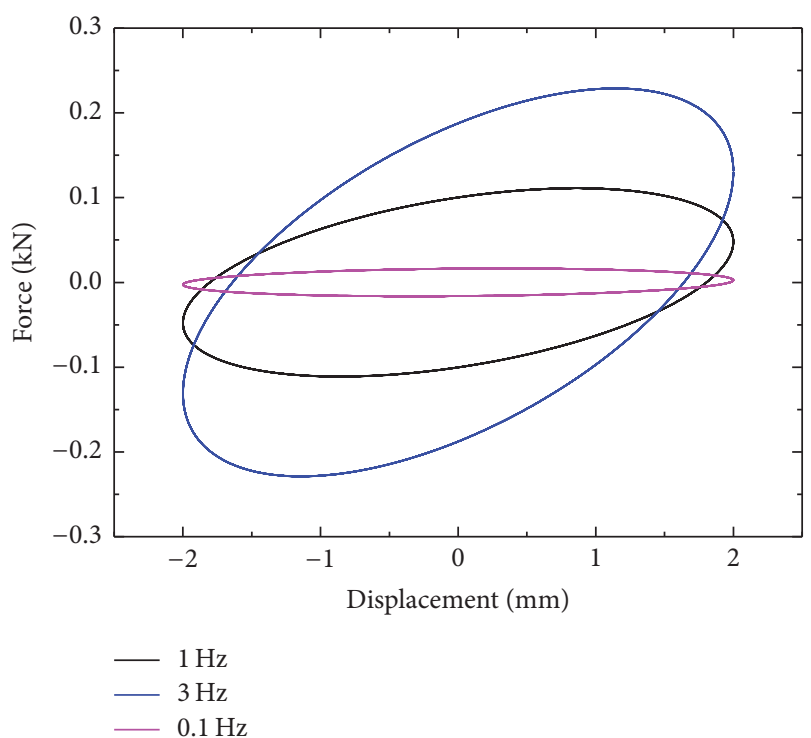

Figure 3: The force-displacement loop of FDM.

$$
\begin{aligned}
& \boldsymbol{\Gamma}=\left\{\begin{array}{lll}
\mathbf{0}_{n \times 1} & 1 & 0
\end{array}\right\}^{T}, \\
& \boldsymbol{\gamma}=\left\{\begin{array}{lll}
\mathbf{0}_{n \times 1} & 0 & 1
\end{array}\right\}^{T} .
\end{aligned}
$$

$\mathbf{M}_{s}, \mathbf{K}_{s}$, and $\mathbf{C}_{s}$ are the mass, stiffness, and damping matrices of the superstructure, respectively. $I_{i}$ is the mass moment of inertia of the $i$ th story level. The foundation is treated as a rigid cylinder of radius $R$, embedment depth $E$, mass $m_{0}$, and mass moment of inertia $I_{0}$. The coefficients $K_{h h}, K_{h r}$, and $K_{r r}$ are the frequency-dependent foundation stiffness and $C_{h h}, C_{h r}$, and $C_{r r}$ are the frequency-dependent radiation damping coefficient. The impedance functions of the embedment foundation used in this paper are calculated by the method proposed by Novak and Sachs [19]. $\psi$ represents the column vector where each element is unity and $\Lambda$ is the column vector of bottom foundation to story heights. $H_{u}(\bar{\omega})$ and $H_{\phi}(\bar{\omega})$ represent the transfer function of the translational and rocking component of the foundation input motion.

2.3. The Effective Input Power Spectrum Density. In earthquake engineering, the earthquake excitation is usually characterized by the well-known Kanai-Tajimi filtered whitenoise spectrum [20], which is given by

$$
S_{g}(\bar{\omega})=\frac{1+4 \xi_{g}^{2}\left(\bar{\omega} / \omega_{g}\right)^{2}}{\left[1-\left(\bar{\omega} / \omega_{g}\right)^{2}\right]^{2}+4 \xi_{g}^{2}\left(\bar{\omega} / \omega_{g}\right)^{2}} S_{0}
$$

where $S_{0}$ is the spectrum of white-noise bedrock acceleration and $\omega_{g}$ and $\xi_{g}$ are the resonant frequency and damping ratio of the soil.

However, the Kanai-Tajimi model exaggerates the energy of low frequency vibration, which may cause unreasonable results. Some researchers $[21,22]$ have proposed modification 
methods. Hu introduced a cut frequency parameter $\omega_{c}$ to modify the Kanai-Tajimi model:

$$
S_{g}(\bar{\omega})=\frac{1+4 \xi_{g}^{2}\left(\bar{\omega} / \omega_{g}\right)^{2}}{\left[1-\left(\bar{\omega} / \omega_{g}\right)^{2}\right]^{2}+4 \xi_{g}^{2}\left(\bar{\omega} / \omega_{g}\right)^{2}} \cdot \frac{\bar{\omega}^{6}}{\bar{\omega}^{6}+\omega_{c}^{6}} S_{0} .
$$

$S_{0}$ can be obtained by the following equation:

$$
S_{0}=\frac{a_{\max }^{2}}{f^{2} \omega_{e}}
$$

where $a_{\max }$ represents the peak value of input acceleration; $f$ represents peak factor; $\omega_{c}$ denotes the spectral area when $S_{0}=1$, which is given by

$$
=\int_{0}^{\infty} \frac{1+4 \xi_{g}^{2}\left(\bar{\omega} / \omega_{g}\right)^{2}}{\left[1-\left(\bar{\omega} / \omega_{g}\right)^{2}\right]^{2}+4 \xi_{g}^{2}\left(\bar{\omega} / \omega_{g}\right)^{2}} \cdot \frac{\bar{\omega}^{6}}{\bar{\omega}^{6}+\omega_{c}^{6}} d \bar{\omega} .
$$

The covering soil on the bedrock is considered as the homogeneous viscoelastic and isotropic half-space as mentioned previously, and thus the resonant frequency of the soil can be easily obtained:

$$
\omega_{g}=\frac{\pi V_{s}}{2 H}
$$

where $H$ denotes the height from the soil surface to the bedrock and $V_{s}$ denotes the shear velocity of the soil.

The damping ratio of field soil is a relatively complicated problem. According to the previous study, $\xi_{g}$ varies in the range $0.64 \sim 0.9$ for different site categories determined by the equivalent shear velocity of soil and the overburden thickness. For the sake of simplicity, the damping ratio $\xi_{g}$ used in this paper is defined as follows: when $V_{s}=500 \mathrm{~m} / \mathrm{s}$, $\xi_{g}=0.64$; when $V_{s}=100 \mathrm{~m} / \mathrm{s}, \xi_{q}=0.9$; the intermediate range is obtained by linearization technique.

Figure 4 gives the PSDF of the free field with different shear velocity of soil, overburden thickness $H=40 \mathrm{~m}$, peak input acceleration $a_{\max }=35 \mathrm{gal}$, and cut frequency $\omega_{c}=$ $1.7 \mathrm{rad} / \mathrm{s}$. For different soil conditions, the value of peak factor $f$ is almost the same according to Liu and Fang [23], and $f=3$ is considered herein for all cases.

In the evaluation of seismic response for structures considering SSI effect, the base-slab motion is commonly assumed to match the free-field motion. However, the actual base-slab motions deviate from free-field motions as a result of soil-foundation kinematic interaction. The presence of stiff foundation elements on or in the soil causes foundation motions to deviate from free-field motions as a result of ground motion incoherence, wave inclination. The kinematic effects are often described by a frequency-dependent transfer function relating the free-field motion to the foundation input motion (FIM), which is the motion that would be experienced by the foundation if it and the supported structure are massless. The FIM consists of translational and rotational components. Translational motions are reduced relative to

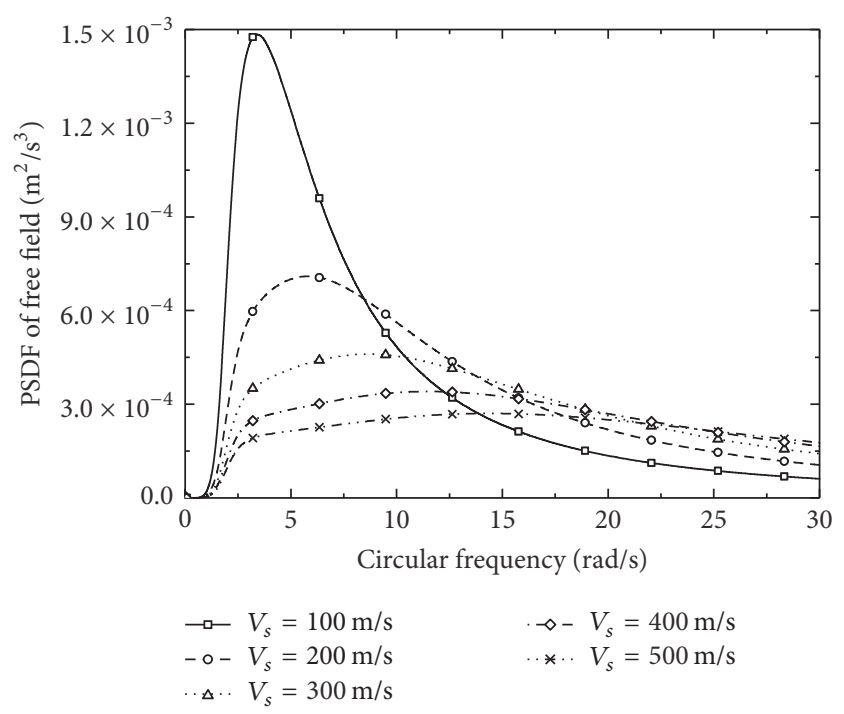

FIGURE 4: The PSDF of free field for different shear velocities of soil.

the free field, primarily in the horizontal components. The rotational components are introduced as a result of variations in ground motion along the foundation due to inclined or incoherent waves. For simplifying the analysis, the kinematic interaction mechanism is considered as a low pass filter which reduces the translational component of the free-field motion but generates rocking and torsional component. If the propagating mechanism is considered as vertically propagating plane shear waves only, the torsional component can be neglected. The Fourier amplitude relationships between the free-field displacement $U_{g}^{f}$ and the translational and rocking component (denoted as $U_{h}^{f}$ and $U_{r}^{f}$, resp.) are simply defined by Harada et al. [24] as follows.

\section{The Translational Component}

$$
U_{h}^{f}=U_{g}^{f} \begin{cases}{\left[\frac{\sin \left(\bar{\omega} E / V_{s}\right)}{\bar{\omega} E / V_{s}}\right]^{2}} & \bar{\omega} \leq \omega_{n} \\ 0.405 & \bar{\omega}>\omega_{n} .\end{cases}
$$

The Rocking Component

$$
\begin{aligned}
& \text { If } \bar{\omega} \leq \omega_{n}, \\
& \quad U_{r}^{f} \\
& =\frac{U_{g}^{f}}{R}\left\{\begin{array}{cl}
0.4 \frac{E}{R}\left(1-\cos \frac{\bar{\omega} E}{V_{s}}\right) & \frac{E}{R} \leq 1 \\
\left(0.405-0.05 \frac{E}{R}\right)\left(1-\cos \frac{\bar{\omega} E}{V_{s}}\right) & \frac{E}{R}>1
\end{array}\right\} .
\end{aligned}
$$

If $\bar{\omega}>\omega_{n}$

$$
U_{r}^{f}=\frac{U_{g}^{f}}{R}\left\{\begin{array}{cc}
0.4 \frac{E}{R} & \frac{E}{R} \leq 1 \\
0.405-0.05 \frac{E}{R} & \frac{E}{R}>1
\end{array}\right\},
$$

where $\omega_{n}=\pi V_{s} / 2 E$. 


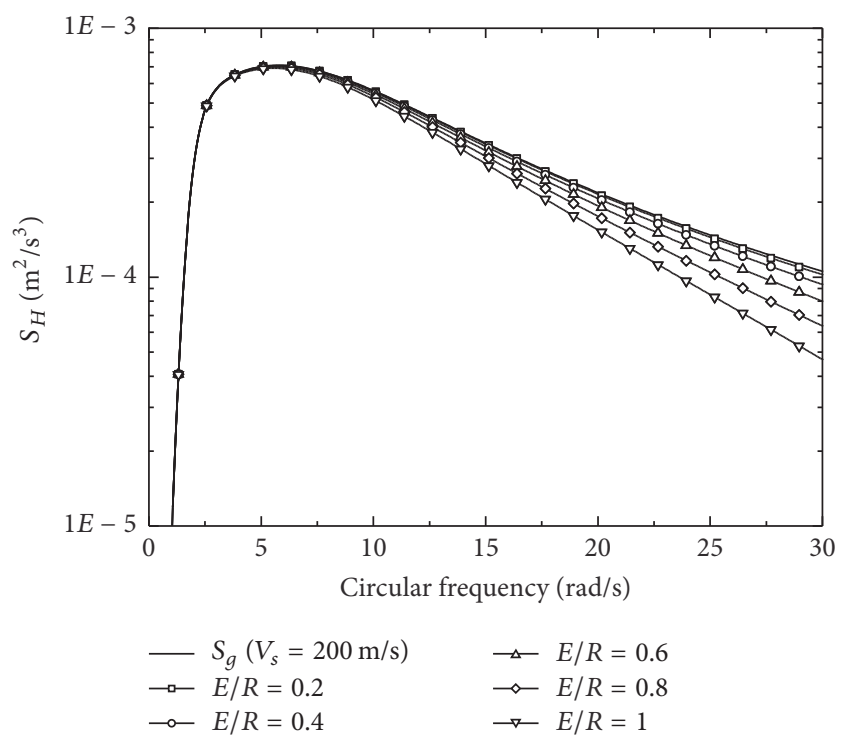

FIgURE 5: The translational PSDF component.

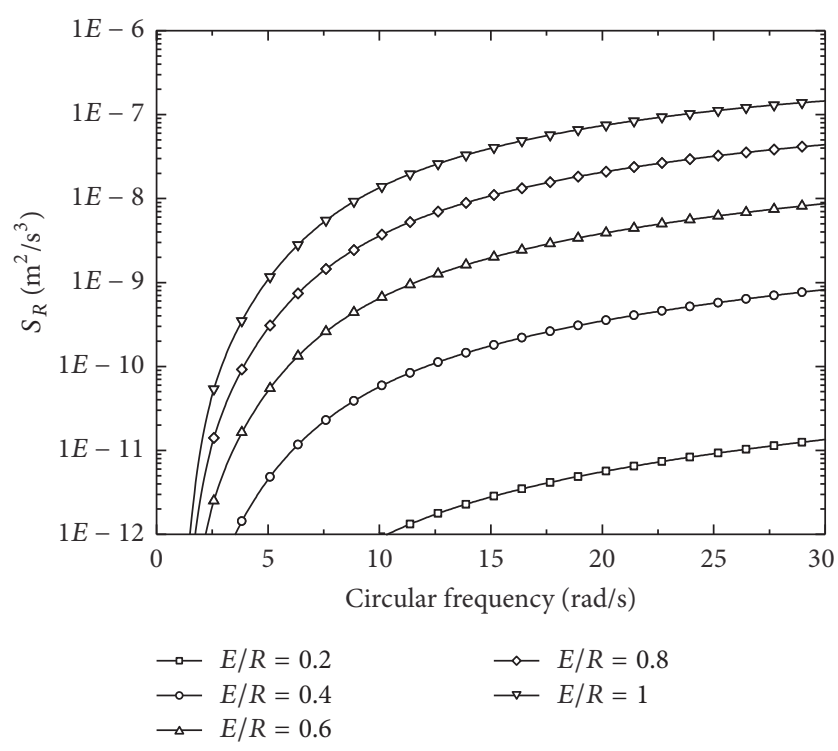

FIGURE 6: The rocking PSDF component.

According to the relationship between power spectrum density function and the Fourier spectrum function, the PSDF of the translational and rocking PSDF component $S_{H}$ and $S_{R}$ can be easily obtained through the above equations. Figures 5 and 6 give the translational and rocking PSDF component when $V_{s}=200 \mathrm{~m} / \mathrm{s}$; five different embedment ratios are considered $(E / R=0.2,0.4,0.6,0.8$, and 1 , resp.). As illustrated by the figures, with the increase of foundation embedment ratio, the kinematic interaction between foundation and soil is more obvious. The horizontal component in high frequency range decreases compared with the free-field PSDF, meanwhile generating rotational component.

2.4. The Response of the System. The pseudo-excitation algorithm is used to obtain the structural response. The earthquake random excitations can be converted to a series of harmonic excitations. The pseudo-excitation is constituted as follows:

$$
\ddot{u}_{g}(t)=\sqrt{S_{g}(\bar{\omega})} e^{i \bar{\omega} t}
$$

Equation (8) can also be written in the following form:

$$
\mathbf{H}_{0}(\bar{\omega}) \mathbf{U}(\bar{\omega})=\left\{\boldsymbol{\Gamma} \cdot H_{u}(\bar{\omega})+\gamma \cdot H_{\phi}(\bar{\omega})\right\} \ddot{U}_{g}(\bar{\omega}),
$$

in which

$$
\mathbf{H}_{0}(\bar{\omega})=\left\{-\bar{\omega}^{2}[\mathbf{I}]+i \bar{\omega}[\mathbf{C}][\mathbf{M}]^{-1}+[\mathbf{K}][\mathbf{M}]^{-1}\right\}^{-1} .
$$

Then, the mean square response value of the system can be obtained by the following expressions.

The Mean Square Response Value of Story Displacement

$$
\sigma_{U_{j}}^{2}=\sigma_{u_{j}}^{2}+\sigma_{u_{b}}^{2}+h_{j}^{2} \sigma_{u_{r}}^{2},
$$

where

$$
\begin{aligned}
\sigma_{u_{j}}^{2} & =\int_{0}^{\infty}\left|\mathbf{H}_{0}(\bar{\omega})_{j, n+1}\right|^{2} S_{H}(\bar{\omega}) \\
& +\left|\mathbf{H}_{0}(\bar{\omega})_{j, n+2}\right|^{2} S_{R}(\bar{\omega}) d \bar{\omega} \\
\sigma_{u_{b}}^{2} & =\int_{0}^{\infty}\left|\mathbf{H}_{0}(\bar{\omega})_{n+1, n+1}\right|^{2} S_{H}(\bar{\omega}) \\
& +\left|\mathbf{H}_{0}(\bar{\omega})_{n+1, n+2}\right|^{2} S_{R}(\bar{\omega}) d \bar{\omega} \\
\sigma_{u_{r}}^{2} & =\int_{0}^{\infty}\left|\mathbf{H}_{0}(\bar{\omega})_{n+2, n+1}\right|^{2} S_{H}(\bar{\omega}) \\
& +\left|\mathbf{H}_{0}(\bar{\omega})_{n+2, n+2}\right|^{2} S_{R}(\bar{\omega}) d \bar{\omega} .
\end{aligned}
$$

The Mean Square Response Value of Story Absolute Acceleration

$$
\sigma_{A_{j}}^{2}=\sigma_{a_{j}}^{2}+\sigma_{a_{b}}^{2}+h_{j}^{2} \sigma_{a_{r}}^{2}+S_{H}(\bar{\omega})+S_{R}(\bar{\omega}) h_{j}^{2},
$$

where

$$
\begin{aligned}
\sigma_{a_{j}}^{2} & =-\int_{0}^{\infty} \bar{\omega}^{2}\left|\mathbf{H}_{0}(\bar{\omega})_{j, n+1}\right|^{2} S_{H}(\bar{\omega}) \\
& +\bar{\omega}^{2}\left|\mathbf{H}_{0}(\bar{\omega})_{j, n+2}\right|^{2} S_{R}(\bar{\omega}) d \bar{\omega} \\
\sigma_{a_{b}}^{2} & =-\int_{0}^{\infty} \bar{\omega}^{2}\left|\mathbf{H}_{0}(\bar{\omega})_{n+1, n+1}\right|^{2} S_{H}(\bar{\omega}) \\
& +\bar{\omega}^{2}\left|\mathbf{H}_{0}(\bar{\omega})_{n+1, n+2}\right|^{2} S_{R}(\bar{\omega}) d \bar{\omega} \\
\sigma_{a_{r}}^{2} & =-\int_{0}^{\infty} \bar{\omega}^{2}\left|\mathbf{H}_{0}(\bar{\omega})_{n+2, n+1}\right|^{2} S_{H}(\bar{\omega}) \\
& +\bar{\omega}^{2}\left|\mathbf{H}_{0}(\bar{\omega})_{n+2, n+2}\right|^{2} S_{R}(\bar{\omega}) d \bar{\omega} .
\end{aligned}
$$


The Mean Square Response Value of Interstory Drift

$$
\begin{aligned}
& \text { For } j=1 \\
& \begin{aligned}
\sigma_{\theta_{j}}^{2} & =\frac{1}{h_{0}^{2}} \int_{0}^{\infty}\left|\mathbf{H}_{0}(\bar{\omega})_{j, n+1}\right|^{2} S_{H}(\bar{\omega}) \\
& +\left|\mathbf{H}_{0}(\bar{\omega})_{j, n+2}\right|^{2} S_{R}(\bar{\omega}) d \bar{\omega}+\frac{h_{j}^{2}}{h_{0}^{2}} \\
& \cdot \int_{0}^{\infty}\left|\mathbf{H}_{0}(\bar{\omega})_{n+2, n+1}\right|^{2} S_{H}(\bar{\omega}) \\
& +\left|\mathbf{H}_{0}(\bar{\omega})_{n+2, n+2}\right|^{2} S_{R}(\bar{\omega}) d \bar{\omega} .
\end{aligned}
\end{aligned}
$$

For $j=2,3, \ldots, N$,

$$
\begin{aligned}
\sigma_{\theta_{j}}^{2} & =\frac{1}{h_{0}^{2}} \int_{0}^{\infty}\left|\mathbf{H}_{0}(\bar{\omega})_{j, n+1}-\mathbf{H}_{0}(\bar{\omega})_{j-1, n+1}\right|^{2} S_{H}(\bar{\omega}) \\
& +\left|\mathbf{H}_{0}(\bar{\omega})_{j, n+2}-\mathbf{H}_{0}(\bar{\omega})_{j-1, n+2}\right|^{2} S_{R}(\bar{\omega}) d \bar{\omega} \\
& +\frac{h_{j}^{2}-h_{j-1}^{2}}{h_{0}^{2}} \int_{0}^{\infty}\left|\mathbf{H}_{0}(\bar{\omega})_{n+2, n+1}\right|^{2} S_{H}(\bar{\omega}) \\
& +\left|\mathbf{H}_{0}(\bar{\omega})_{n+2, n+2}\right|^{2} S_{R}(\bar{\omega}) d \bar{\omega} .
\end{aligned}
$$

According to the random vibration theory, for a stationary random process with mean value of zero, the maximum statistical value of the structural response can be evaluated by the following expressions:

$$
\begin{aligned}
& \mu_{U_{j}}=\left[\sqrt{2 \ln (v T)}+\frac{0.5772}{\sqrt{2 \ln (v T)}}\right] \sigma_{U_{j}} \\
& \mu_{A_{j}}=\left[\sqrt{2 \ln (v T)}+\frac{0.5772}{\sqrt{2 \ln (v T)}}\right] \sigma_{A_{j}} \\
& \mu_{\theta_{j}}=\left[\sqrt{2 \ln (v T)}+\frac{0.5772}{\sqrt{2 \ln (v T)}}\right] \sigma_{\theta_{j}},
\end{aligned}
$$

where $\mu_{U_{j}}, \mu_{A_{j}}$, and $\mu_{\theta_{j}}$ are the maximum statistical value of displacement, acceleration, and drift of the $j$ th floor, respectively. $T$ is the duration of earthquake and $v$ is the zero crossing rate, which can be obtained by

$$
v=\frac{1}{\pi}\left(\frac{\lambda_{2}}{\lambda_{0}}\right)^{1 / 2}
$$

where $\lambda_{0}$ and $\lambda_{2}$ are the zero- and second-order spectral moment.
TABLE 1: Characteristics of structures.

\begin{tabular}{lcccc}
\hline \multirow{2}{*}{ Story } & \multicolumn{2}{c}{10 floors } & \multicolumn{2}{c}{20 floors } \\
& Stiffness $(\mathrm{MN} / \mathrm{m})$ & Period & Stiffness $(\mathrm{MN} / \mathrm{m})$ & Period \\
\hline 1 & 537 & 0.719 & 1280 & 1.030 \\
2 & 473 & 0.265 & 1280 & 0.389 \\
3 & 435 & 0.164 & 970 & 0.237 \\
4 & 408 & 0.121 & 923 & 0.172 \\
5 & 404 & 0.098 & 846 & 0.135 \\
6 & 320 & 0.083 & 792 & 0.111 \\
7 & 298 & 0.073 & 748 & 0.096 \\
8 & 289 & 0.067 & 710 & 0.085 \\
9 & 244 & 0.060 & 710 & 0.076 \\
10 & 191 & 0.054 & 680 & 0.070 \\
11 & - & - & 612 & 0.066 \\
12 & - & - & 577 & 0.061 \\
13 & - & - & 543 & 0.057 \\
14 & - & - & 485 & 0.054 \\
15 & - & - & 441 & 0.051 \\
16 & - & - & 413 & 0.048 \\
17 & - & - & 409 & 0.045 \\
18 & - & - & 320 & 0.042 \\
19 & - & - & 298 & 0.039 \\
20 & - & - & & 0.035 \\
\hline
\end{tabular}

\section{Optimal Locations of VEDs}

The optimal design of VEDs in structures considering SSI effect under random earthquake excitation is illustrated using two typical frame structures originating from the actual project. The basic properties of the structures are listed in Table 1. The height of each floor and the bay width of the frame are taken as $3.6 \mathrm{~m}$ and $10 \mathrm{~m}$, respectively. For 10 -story structures, three cases of embedment ratios $(E / R=1 / 3,2 / 3$, and 1$)$ and one foundation radius $(R=7.5 \mathrm{~m})$ are considered; for 20-story structures, also three cases of embedment ratios $(E / R=1 / 3,2 / 3$, and 1$)$ are considered but with a larger foundation radius $(R=15 \mathrm{~m})$. Mass of each floor is 120 tons for both structures. In all the analysis, the viscous damping matrix of the superstructure is assumed to be proportional to the mass and stiffness metrics of the frame structure. The first two modal damping ratios are set to be 0.05 . Five types of site classes are considered $\left(V_{s}=150 \mathrm{~m} / \mathrm{s}, 200 \mathrm{~m} / \mathrm{s}, 250 \mathrm{~m} / \mathrm{s}\right.$, $300 \mathrm{~m} / \mathrm{s}$, and $400 \mathrm{~m} / \mathrm{s}$ ). Poisson's ratio of soil $v_{s}=1 / 3$ and the mass density $\rho_{s}=1700 \mathrm{~kg} / \mathrm{m}^{3}$.

The response quantities of interest are the maximum statistical response values of displacement, absolute acceleration, and interstory drifts of structures with and without VEDs. The energy dissipation effect can be evaluated by the reduction ratio $R_{0}$, which is defined as the maximum statistical response values of the structure with VEDs divided by the maximum statistical response values of the structure without VEDs. Therefore, the damping effect is better for 
smaller value of $R_{0}$. The structural drift reduction ratio $R_{\theta}$, displacement reduction ratio $R_{d}$, absolute acceleration reduction ratio $R_{a}$, and the mean response quantities reduction ratio $R_{\text {mean }}$ are defined by the following:

$$
\begin{aligned}
R_{\theta} & =\frac{\max \left\{\mu_{\theta_{j}}\right\}_{\mathrm{VED}}}{\max \left\{\mu_{\theta_{j}}\right\}_{\mathrm{No}-\mathrm{VED}}} \\
R_{d} & =\frac{\max \left\{\mu_{U_{j}}\right\}_{\mathrm{VED}}}{\max \left\{\mu_{U_{j}}\right\}_{\mathrm{No}-\mathrm{VED}}} \\
R_{a} & =\frac{\max \left\{\mu_{A_{j}}\right\}_{\mathrm{VED}}}{\max \left\{\mu_{A_{j}}\right\}_{\mathrm{No}-\mathrm{VED}}} \\
R_{\text {mean }} & =\frac{R_{a}+R_{d}+R_{\theta}}{3} .
\end{aligned}
$$

In order to primarily determine the total amount of VED for optimal design, the damper is firstly uniformly distributed along the height of the structure. For each floor, the amount of viscoelastic material is the same. The parameter $c_{0}$ of the VED plays a leading role in the damping forces of the damper, which can be gradually changed by altering the shear area $A$ and shear thickness $d$ of the damper. Thus, in the following analysis, the parameter $c_{0}$ is considered as an optimization variable. Figures 7 and 8 give the variations of $R_{\theta}, R_{d}, R_{a}$, and $R_{\text {mean }}$ with the change of $c_{0}$ for different soil cases. In these pictures, $c_{0}$ represents the amount of viscoelastic material for each floor. The embedment ratio $E / R=1$. The peak acceleration of input earthquake is 35 gal.

It is indicated by these figures that, with the increase of $c_{0}$, the reduction ratios of drifts, displacement, and absolute acceleration decrease for all soil types. The VEDs have the best control of the structural response for structures resting on fixed bases, and the control efficiency of VEDs deteriorates within the consideration of SSI effect. The decreased degree of the control efficiency is higher as the soil becomes softer.

As illustrated in Figure 7, when $c_{0}=1.5 \times 10^{4} \mathrm{kN} / \mathrm{m}$, approximately $50 \%$ the mean response reduction $R_{\text {mean }}$ is obtained for fixed base cases; however, the corresponding reduction is only about $85 \%$ for a rather soft soil condition $\left(V_{s}=150 \mathrm{~m} / \mathrm{s}\right)$ when SSI effect is taken into consideration.

The foundation embedment ratio is an important factor that has a significant influence upon the effect of soilstructure interaction, and thus the performance of VEDs will then be affected. Figures 9 and 10 depict the mean reduction ratio $R_{\text {mean }}$ for three embedment ratios $(E / R=1 / 3,2 / 3$, and 1 , resp.) with different soil types.

The figures reveal that the efficiency of the VEDs is closely related to the foundation embedment; with the increase of foundation embedment ratio, stronger soil-structure interaction effect occurs, and the control effect of the VEDs dependently decreases. The difference of reduction ratio between the three embedment ratio cases is the largest when $V_{s}=150 \mathrm{~m} / \mathrm{s}$, where the soil-structure interaction effect is the most remarkable. With the increase of soil stiffness, the difference gradually decreases. For 20-story structures, the difference between the three different embedment ratios is more significant than that of 10 -story structures, owing to the fact that the SSI effect is more intense for taller structures.

These observations above are used as initial design parameters for structural response control, and then the total amount of viscoelastic material decided for a certain reduction ratio is redistributed to find the best placement schemes where the minimum value of $R_{\text {mean }}$ is achieved. For example, a tentative maximum reduction value of $R_{\text {mean }}=$ $70 \%$ is achieved when $c_{0}=2.9 \times 10^{4} \mathrm{kN} / \mathrm{m}$ of each floor for $V_{s}=150 \mathrm{~m} / \mathrm{s}$ as illustrated in Figure 7. Thus, the total amount of viscoelastic material to be redistributed for optimal design of the 10 -story structure is computed as $C_{T}=2.9 \times 10^{5} \mathrm{kN} / \mathrm{m}$.

The problem of location optimization of VEDs can be defined as a procedure of finding the minimum value of $R_{\text {mean }}$ with variations of $c_{0}$ for each floor while keeping the total amount of viscoelastic material constant.

The optimal function is defined as follows:

$$
f(\widetilde{\mathbf{C}})=\frac{R_{d}(\widetilde{\mathbf{C}})+R_{\theta}(\widetilde{\mathbf{C}})+R_{a}(\widetilde{\mathbf{C}})}{3}
$$

The constraint condition is

$$
\begin{aligned}
\sum_{i=1}^{n} \widetilde{\mathbf{C}}_{i}-C_{T} & =0 \\
\widetilde{\mathbf{C}}_{i} & \geq 0,
\end{aligned}
$$

where $\widetilde{\mathbf{C}}=\left[c_{0,1}, c_{0,2}, \ldots, c_{0, n}\right]$ and $C_{T}$ represents the total amount of viscoelastic material for a determined reduction value of $R_{\text {mean }}$, which is obtained from the uniform distribution case.

Determining the optimal design variables $\widetilde{\mathbf{C}}$ for the system is a very complex problem as a result of varying dynamic properties of the system within consideration of the SSI effect and the interaction between dampers and the structure. Moreover, in practical applications, design variables of VEDs may not be continuous functions. Thus, the location optimal design of VEDs can be viewed as a combinational optimization problem since the design space is discrete. In principle, the optimal solution for such a discrete problem can be found by an exhaustive enumerative search of every possible combination of damper locations. However, the practical implementation of this method is not at all effective due to the large number of feasible design combinations.

In order to effectively solve the problem, a genetic algorithm (GA) is adopted as a numerical searching technique. For the past few years, the GA introduced by Holland [25] has been successfully applied to a wide range of engineering applications and proved to be very effective in solving such problems, for its features of evolutionary, multipoint, direct, and parallel searching. The GA is an optimization technique simulating the evolutionary process based on the principles of natural biological evolutionary process where the stronger 

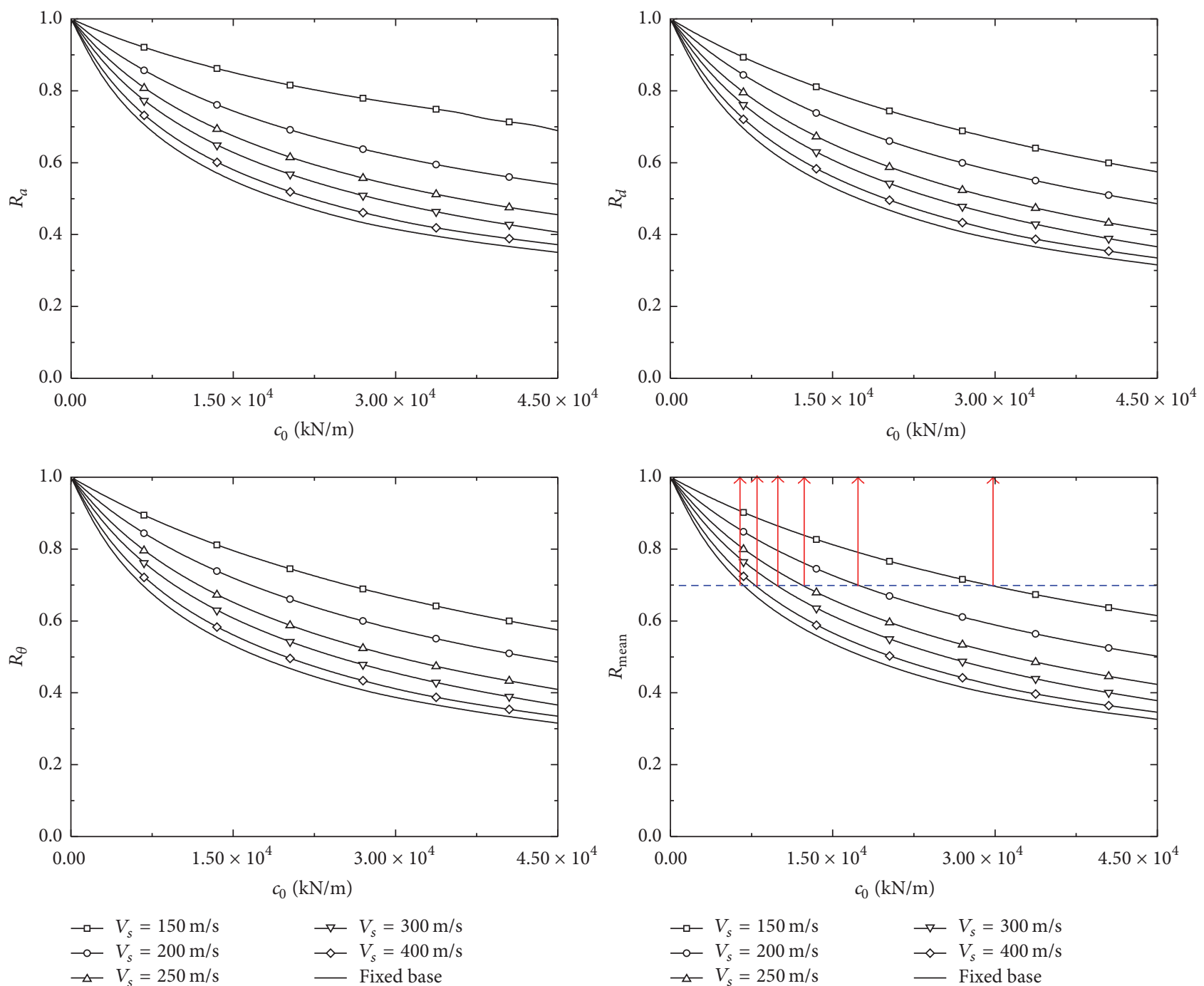

$\begin{array}{ll}\multimap & V_{s}=200 \mathrm{~m} / \mathrm{s} \\ \triangle & V_{s}=250 \mathrm{~m} / \mathrm{s}\end{array}$

_ Fixed base

Figure 7: The reduction ratios for 10-story structures $(E / R=1)$.

individuals are likely to be winners in a competing environment [26-28].

In a genetic algorithm, a population of candidate solutions (called individuals, creatures, or phenotypes) to an optimization problem is evolved toward better solutions. Each candidate solution has a set of properties which can be mutated and altered. Traditionally, solutions are represented in binary as strings of 0 s and 1s. The evolution usually starts from a population of randomly generated individuals, which is an iterative process, where the population in each iteration is called a generation. In each generation, the fitness of every individual in the population is evaluated, which is usually the value of objective function in the optimization problem being solved. The more fit individuals are stochastically selected from the current population, and each individual's genome is modified (recombined and possibly randomly mutated) to form a new generation. The new generation of candidate solutions is then used in the next iteration of the algorithm. Commonly, the algorithm terminates when either a maximum number of generations have been produced or a satisfactory fitness level has been reached for the population.

In this study, binary code with 0 s and $1 \mathrm{~s}$ is employed to represent the design variables of $c_{0}$. The design variables can be encoded by mapping in a certain range using an $n$-bit of binary unsigned integer and the GA starts with an initial population, which comprises $N_{g}$ randomly created binary strings. The following equation can be used to decode a string:

$$
\widetilde{C}_{i}=\widetilde{C}_{\min }+\left(\widetilde{C}_{\max }-\widetilde{C}_{\min }\right) \frac{b_{i}}{2^{n}-1}
$$

where $b_{i}$ is the decimal integer value of binary string for $\widetilde{C}_{i}$.

For both 10-story and 20-story structures, $R_{\text {mean }}=0.7$ is selected as an initial target reduction. The total amount of viscoelastic material $C_{T}$ to be redistributed for optimal design can be obtained in Figures 7 and 8, where the embedment ratio $E / R=1$. Table 2 lists the total amount of viscoelastic material for optimal design. 

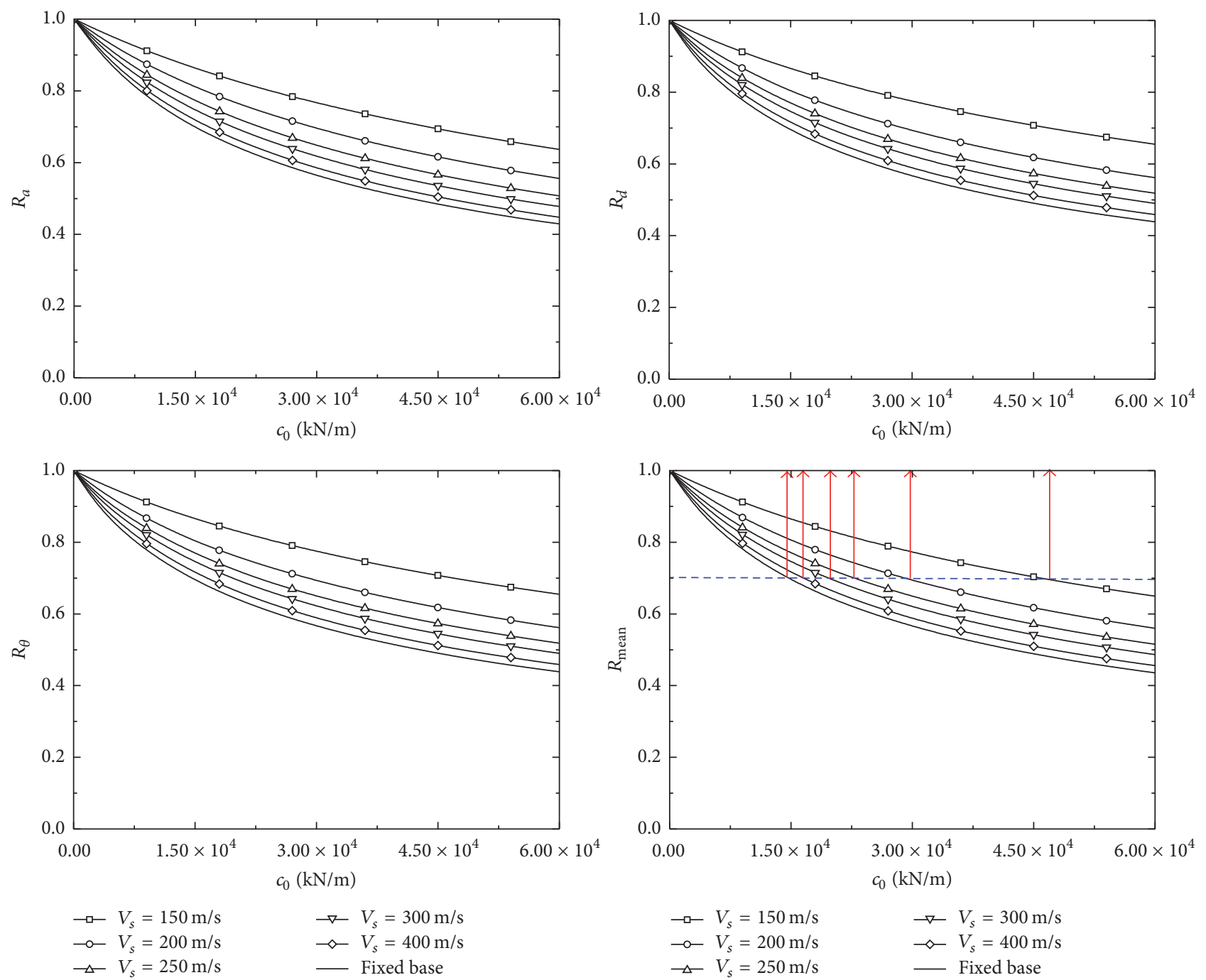

FIGURE 8: The reduction ratios for 20-story structures $(E / R=1)$.

TABLE 2: The total amount of viscoelastic material $C_{T}$ for optimal design.

\begin{tabular}{lccccrr}
\hline Soil type & $V_{s}=150 \mathrm{~m} / \mathrm{s}$ & $V_{s}=200 \mathrm{~m} / \mathrm{s}$ & $V_{s}=250 \mathrm{~m} / \mathrm{s}$ & $V_{s}=300 \mathrm{~m} / \mathrm{s}$ & $V_{s}=400 \mathrm{~m} / \mathrm{s}$ & Fixed base \\
\hline 10 floors & $2.90 E+05$ & $1.80 E+05$ & $1.15 E+05$ & $0.95 E+05$ & $0.75 E+05$ & $0.70 E+05$ \\
20 floors & $9.50 E+05$ & $6.00 E+05$ & $4.70 E+05$ & $3.60 E+05$ & $3.00 E+05$ & $2.90 E+05$ \\
\hline
\end{tabular}

In the application of GA, one population consists of 150 chromosomes $\left(N_{g}=150\right)$, and each chromosome of the population is a string of size $16 n$. Selection is based on roulette wheel selection, the crossover operation is performed with a crossover probability of 0.8 , and mutation operates with a mutation probability of 0.01 .

For an evolutionary process, the individual strings of a population are manipulated cyclically through three basic operations and replacement to produce a new population that tends to have a better fitness value, namely, smaller mean reduction ratio. The placement schemes of the VEDs will be gradually improved as the evolutionary cycle is repeated.

Figures 11 and 12 depict the optimal design results of VEDs with different soil types for 10-story and 20-story structures, respectively. Figures 13 and 14 give the comparison among the optimal results for different soil types.

It is clear from these results that the SSI effect has a great influence on the optimal placement of VEDs. Different soil types will lead to different optimal locations. For 10story structures, the optimal placement of VEDs is mainly concentrated in the range of $4 \sim 6$ floors corresponding to relative hard soil when $V_{s}=400 \mathrm{~m} / \mathrm{s}$; along with the decrease of shear wave velocity of soil, the optimal placement of VEDs has a tendency to shift to top floors; when $V_{s}=150 \mathrm{~m} / \mathrm{s}$, the VEDs are mainly distributed in the range of $6 \sim 10$ floors. The same phenomenon is demonstrated by the optimal locations of VEDs in 20-story structures for different soil types. When $V_{s}=400 \mathrm{~m} / \mathrm{s}$, the VEDs are mainly concentrated in the range 


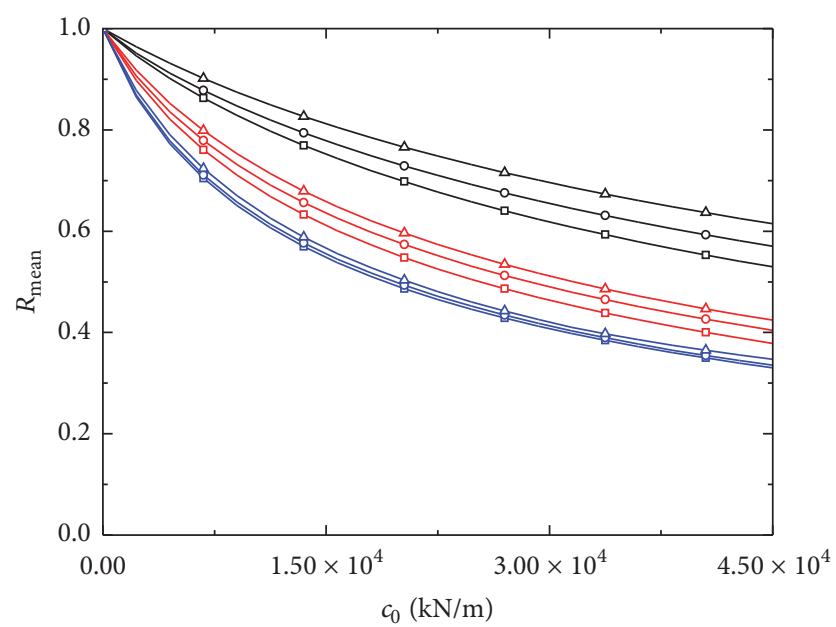
ㅁ $E / R=1 / 3$
- $E / R=2 / 3$
$\begin{aligned}-V_{s} & =150 \mathrm{~m} / \mathrm{s} \\ -V_{s} & =250 \mathrm{~m} / \mathrm{s}\end{aligned}$
$\triangle E / R=1$
$-V_{s}=400 \mathrm{~m} / \mathrm{s}$

FIGURE 9: The mean reduction ratio for structures with various degrees of foundation embedment ratio (10-story structures).

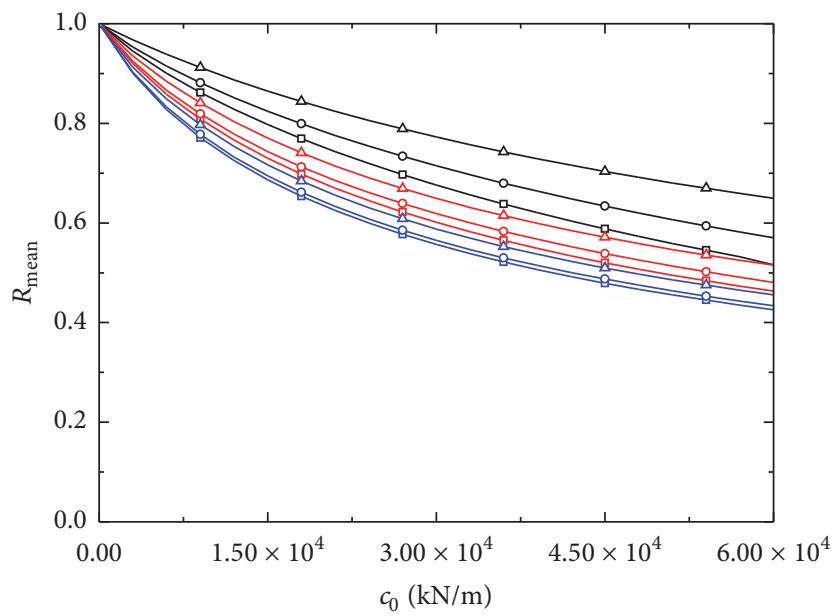
ㅁ $E / R=1 / 3$
○ $E / R=2 / 3$
$\triangle E / R=1$

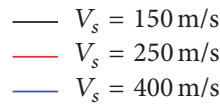

FIGURE 10: The mean reduction ratio for structures with various degrees of foundation embedment ratio (20-story structures).

of $6 \sim 15$ floors; with the decrease of shear velocity of soil, the optimal placement shifts to top floors; when $V_{s}=150 \mathrm{~m} / \mathrm{s}$, the VEDs are mainly distributed in the range of $9 \sim 18$ floors.

Previous studies by other researchers have already revealed that, with the decrease of soil stiffness, the participation of the first-order mode of the system is becoming more and more dominant, in which the mode shape of the system is similar to an inverse triangle and the response of each story gradually increases along the height of the structure. Consequently, the VEDs being arranged on higher floors appear to be more effective as illustrated by the optimization results.

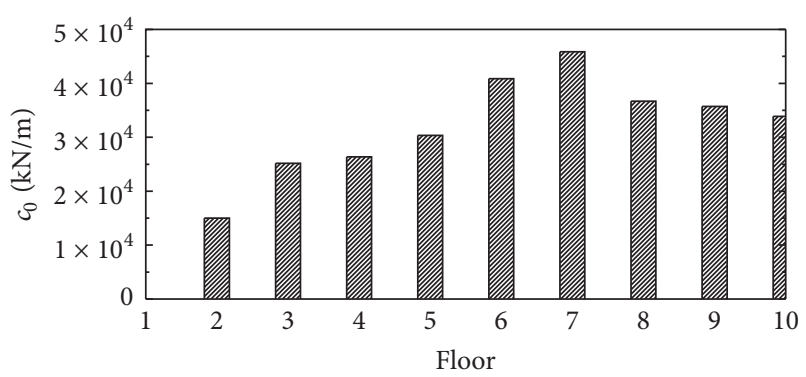

(a) $V_{s}=150 \mathrm{~m} / \mathrm{s}$

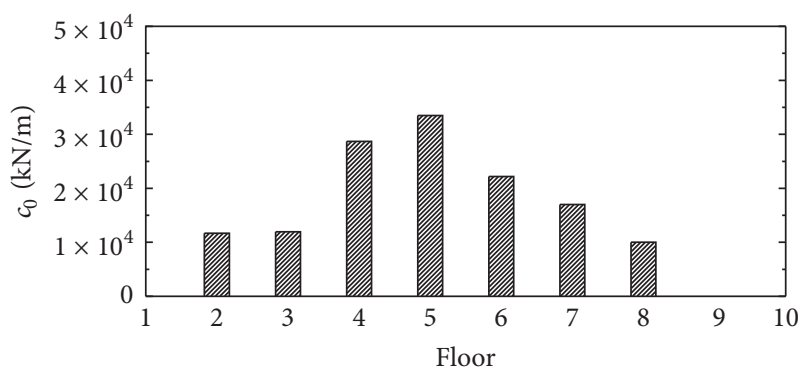

(b) $V_{s}=250 \mathrm{~m} / \mathrm{s}$

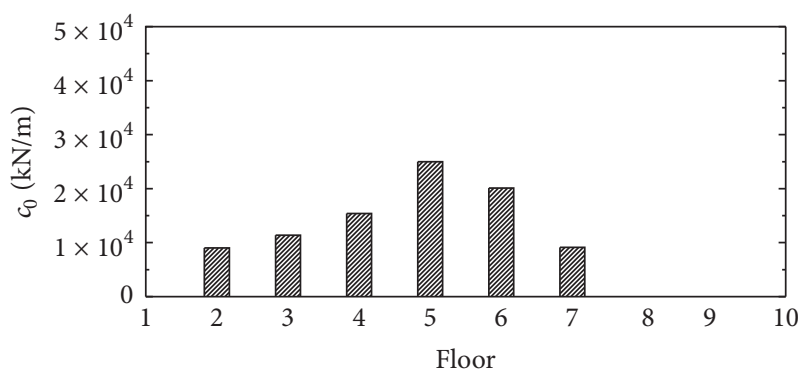

(c) $V_{s}=400 \mathrm{~m} / \mathrm{s}$

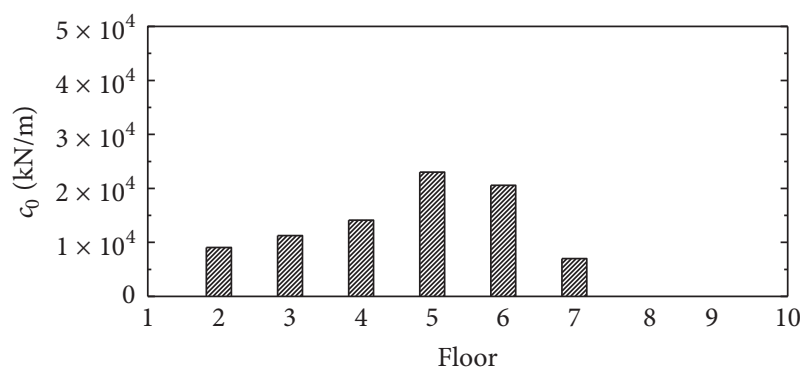

(d) Fixed base

FIGURE 11: The optimal placement schemes of VEDs for different soil types (10-story structure, $E / R=1)$.

The maximum responses of drifts and acceleration for optimal and uniform placement of VEDs are compared in Figures 15 and 16. As the figures show, the optimally placed VEDs provide lower responses of drifts and acceleration in comparison with the uniform placement of VEDs for all cases and the optimization effect differs for different soil types.

For 10-story structures, the maximum story drift decreases by $10.5 \%$ and the maximum acceleration decreases by $12.1 \%$ when $V_{s}=200 \mathrm{~m} / \mathrm{s}$ after optimization; with the increase of soil stiffness, the decreasing degree increases gradually; for fixed base condition, the decreasing degrees 


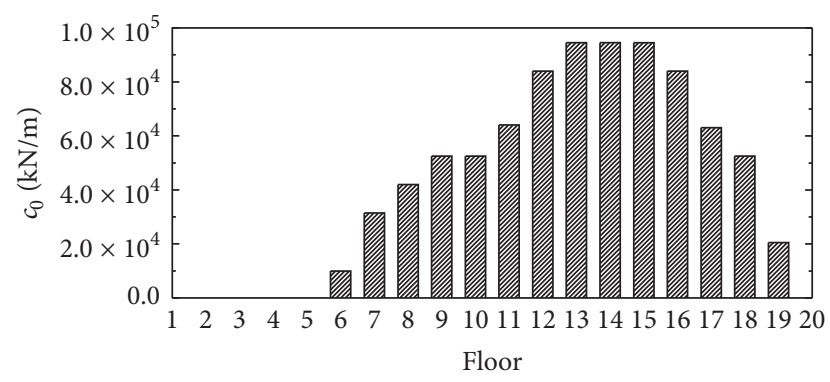

(a) $V_{s}=150 \mathrm{~m} / \mathrm{s}$

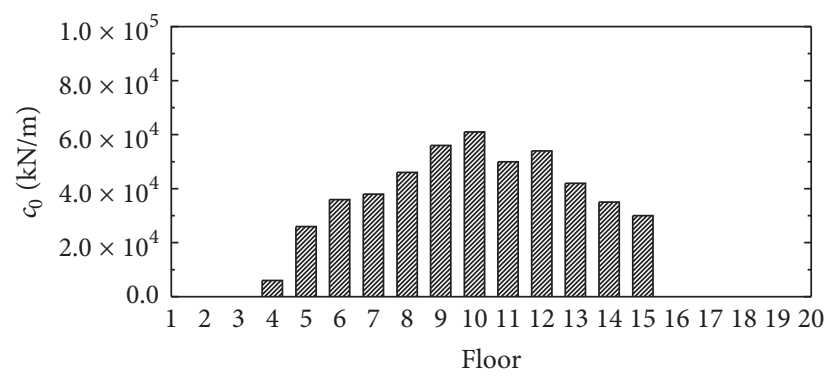

(b) $V_{s}=250 \mathrm{~m} / \mathrm{s}$

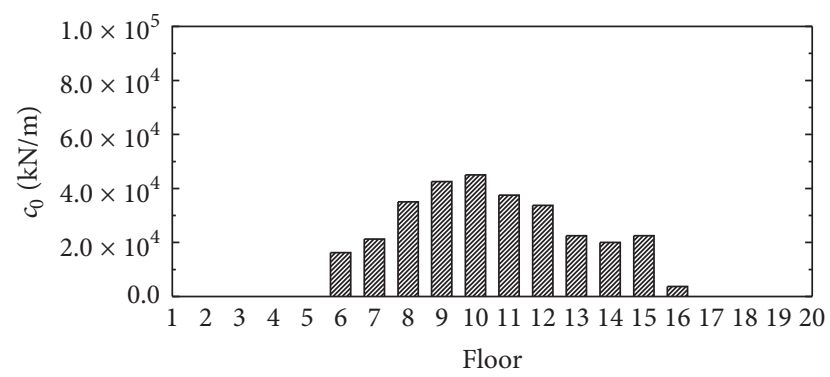

(c) $V_{s}=400 \mathrm{~m} / \mathrm{s}$

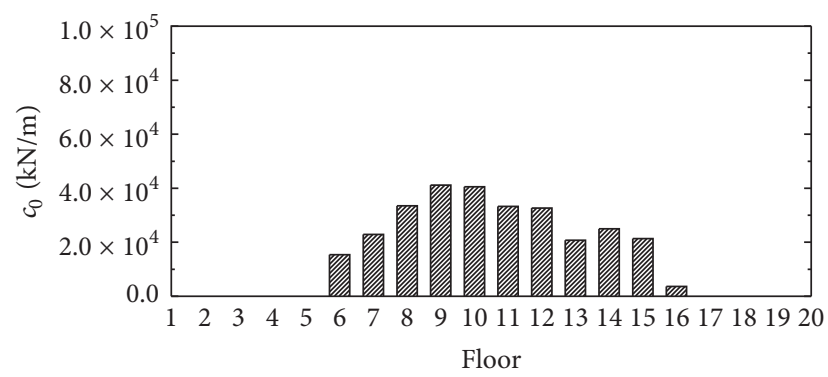

(d) Fixed base

FIGURE 12: The optimal placement schemes of VEDs for different soil types (20-story structure, $E / R=1)$.

of maximum drift and acceleration are $21.6 \%$ and $18.2 \%$, respectively. For 20-story structures, the same control effect of VEDs is demonstrated for different soil types. When $V_{s}$ $=200 \mathrm{~m} / \mathrm{s}$, the maximum story drift decreases by $14.3 \%$ and the maximum acceleration decreases by $16.5 \%$; for fixed base condition, the decreasing degrees of drift and acceleration are about $19.2 \%$ and $20.5 \%$, respectively. The distribution of story drift is more reasonable after optimization, which leads to a full use of viscoelastic material.

Figures 17 and 18 give the comparison of $R_{\text {mean }}$ between structures with optimal and uniform distribution of VEDs for the same total viscoelastic material with different soil types.

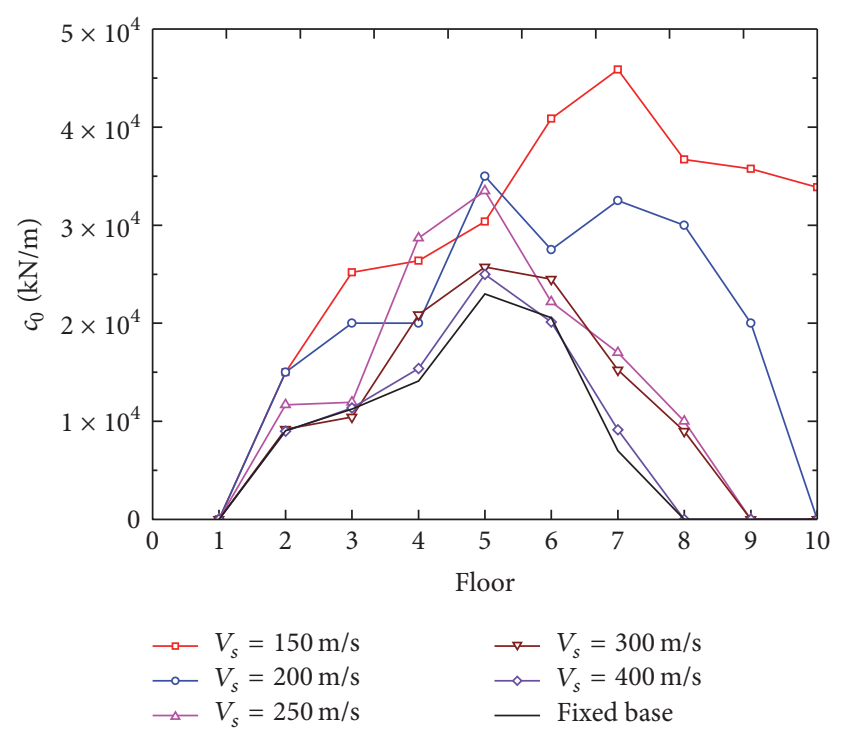

FIGURE 13: The comparison of optimal placement of VEDs among different soil types (10-story structure).

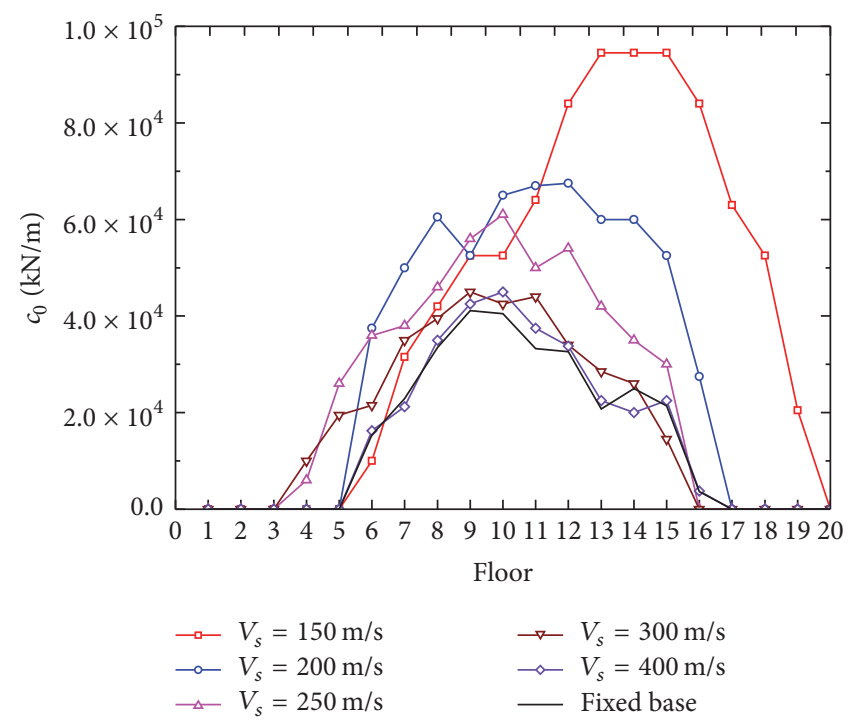

FIGURE 14: The comparison of optimal placement of VEDs among different soil types (20-story structure).

It can be seen from the pictures that the optimal placement of VEDs provides lower reduction ratio than that of the uniform placement schemes for all soil types. With the increase of soil stiffness, the degree of reduction gradually increases and the minimum reduction is achieved for the fixed base condition, where the soil stiffness is assumed to be infinity. The reduction extent between the 10-story and 20-story structures is also different for the same soil conditions. For 10-story structures, when $V_{s}=150 \mathrm{~m} / \mathrm{s}$, the mean reduction ratio $R_{\text {mean }}$ drops from 0.7 to 0.68 after location optimization; for 20-story structures, the mean reduction ratio $R_{\text {mean }}$ drops from 0.7 to 0.64 after location optimization. The results suggest that the optimization effect 


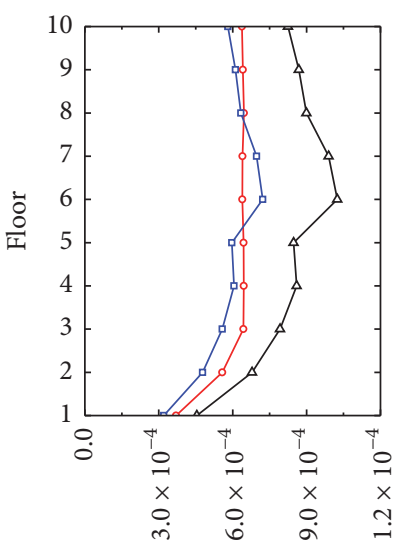

The maximum drift response

-o- Optimal scheme

$\rightarrow-$ Uniform scheme

$\neg$ No VEDs

(a) $V_{s}=200 \mathrm{~m} / \mathrm{s}$
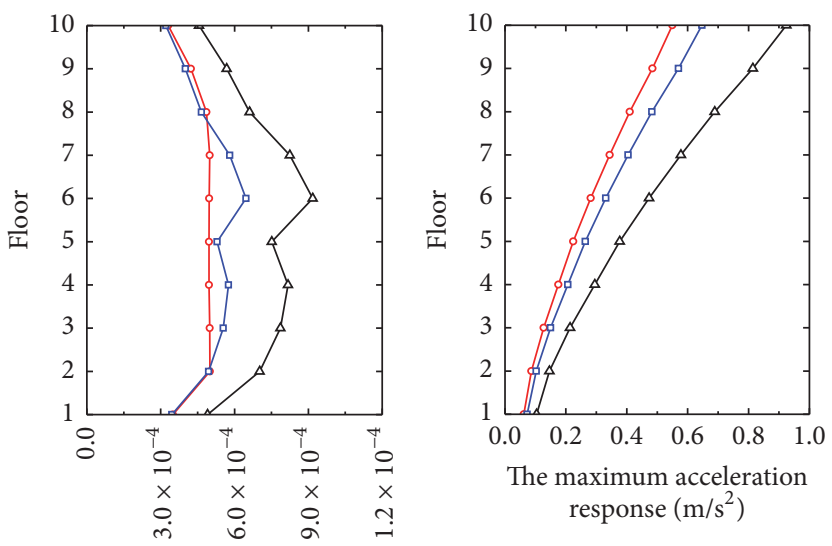

The maximum drift response

- - Optimal scheme

$\rightarrow-$ Uniform scheme

$\neg$ No VEDs

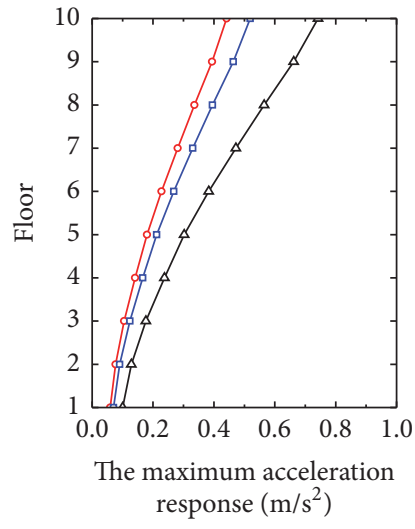

-o- Optimal scheme

$\rightarrow-$ Uniform scheme

$\neg$ No VEDs 


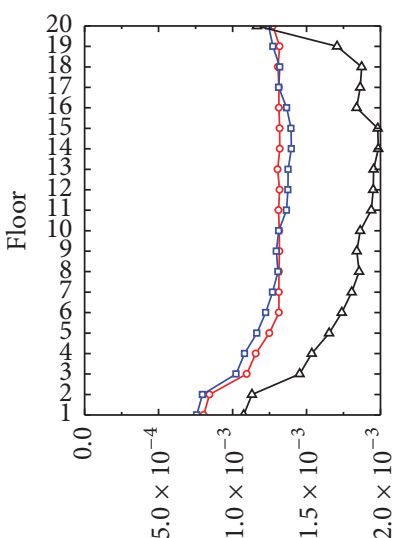

The maximum drift response

$\multimap-$ Optimal scheme

$\rightarrow-$ Uniform scheme

$\neg$ No VEDs

(a) $V_{s}=200 \mathrm{~m} / \mathrm{s}$

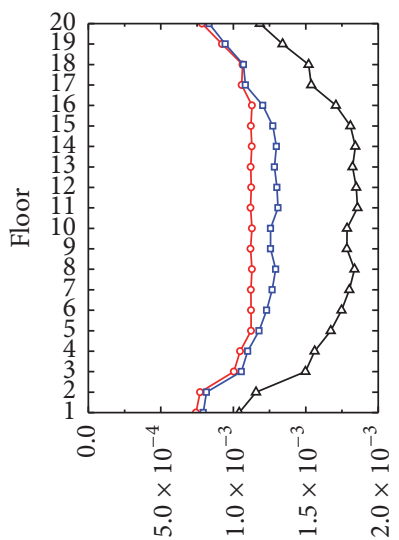

The maximum drift response

$\multimap$ Optimal scheme
$\square-$ Uniform scheme

$\neg$ No VEDs

(b) $V_{s}=400 \mathrm{~m} / \mathrm{s}$
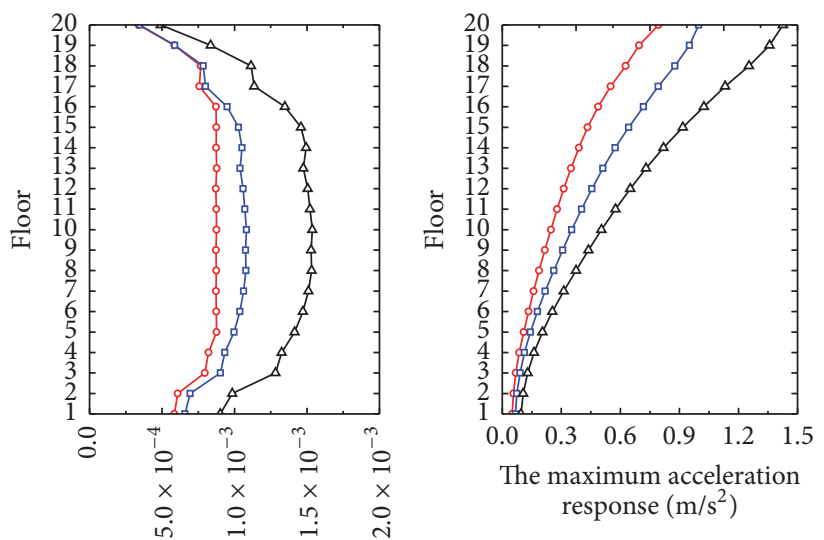

The maximum drift response

- - Optimal scheme

$\neg-$ Uniform scheme

$\triangle$ No VEDs

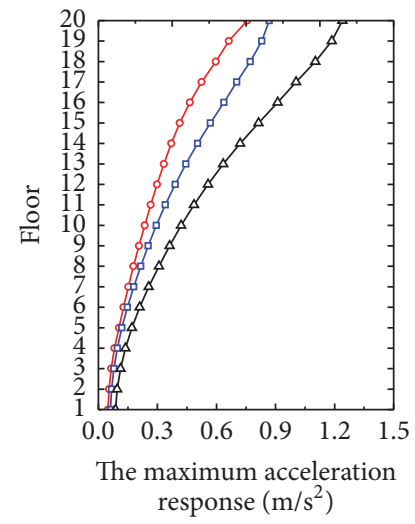

-o- Optimal scheme

$\rightarrow-$ Uniform scheme

$\neg-$ No VEDs 


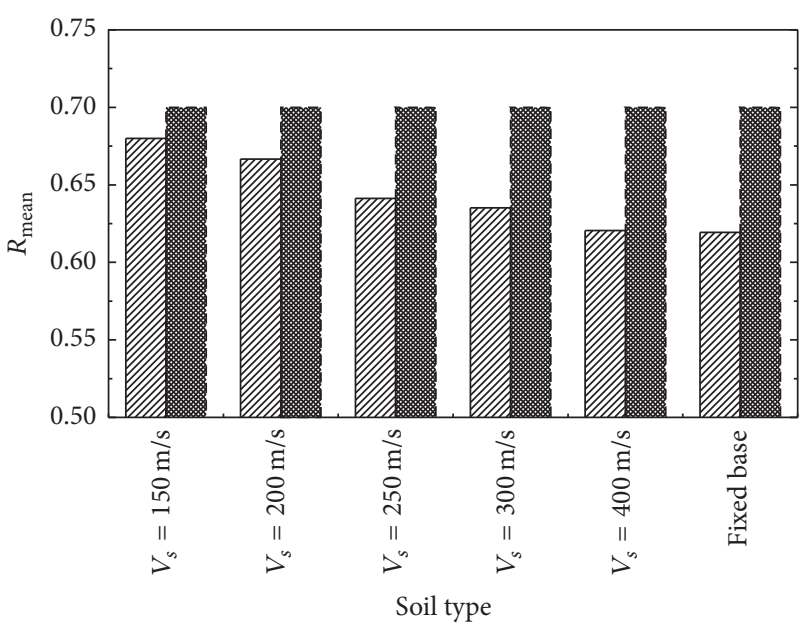

पाI Optimal distribution

Uniform distribution

FIGURE 17: The comparison of $R_{\text {mean }}$ between optimal distribution and uniform distribution of VEDs (10-story structure).

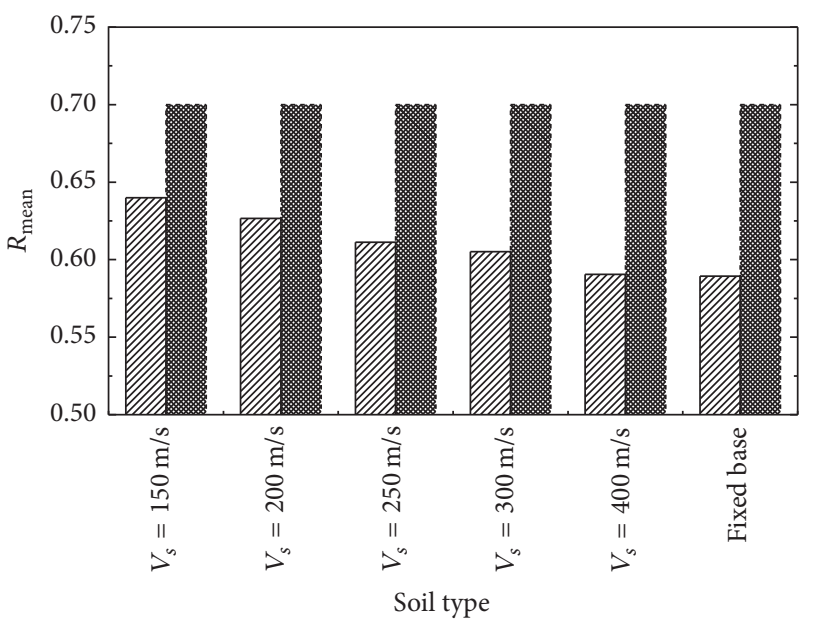

TIIS Optimal distribution

Uniform distribution

FIGURE 18: The comparison of $R_{\text {mean }}$ between optimal distribution and uniform distribution of VEDs (20-story structure).

is better for taller structure, where the space for location optimization is larger.

\section{Conclusions}

Control of the seismic response of elastic multistory frame structures using optimally placed VEDs within consideration of SSI effect is investigated. Responses of the system are obtained in the frequency domain using spectral analysis. The free-field earthquake excitation is assumed to be stationary with mean value of zero and the effective random foundation input motions are acquired by modifying the free-field ground motions based on the kinematic interaction between soil and foundation. Different cases of soil types and foundation embedment ratios are considered as the main parameters that influence the SSI effect and the efficiency of VEDs. The optimization problem is defined as a procedure of finding the minimum reduction ratio $R_{\text {mean }}$ of the system for a determined total amount of viscoelastic material and the optimal locations of VEDs are successfully acquired with the help of genetic algorithm. Two typical elastic multistory frame structures are considered to demonstrate the optimization procedure. Based on the limited numerical studies, the following conclusions can be drawn:

(1) The VEDs have the best control of the structural response for fixed base conditions, and the control efficiency decreases as the soil becomes softer.

(2) Embedment ratio of foundation has a significant influence on the performance of the VEDs. For relative soft soil conditions, the increase of foundation embedment enhances the dynamic interaction between soil and foundation, thus reducing the efficiency of VEDs.

(3) The SSI effect has a great effect on the optimal placement of VEDs in frame structures. For relative hard soil conditions, the optimal locations of VEDs are more concentrated at the middle floors; with the decrease of soil stiffness, the optimal locations have a tendency to shift to top floors.

(4) The optimal placement schemes of VEDs provide lower responses of the system compared with the uniform placement schemes. With the increase of soil stiffness, the optimization effect gradually increases.

\section{Competing Interests}

The authors declare that they have no competing interests.

\section{Acknowledgments}

The authors are grateful for the financial support from the National Natural Science Foundation of China (Grants nos. 51678302 and 51678301), the Jiangsu Province IndustryUniversity-Research Joint Innovation Fund-Prospective Joint Research Project (Grant no. BY2014005-05), and the Major Program of Natural Science Foundation of the Jiangsu Higher Education Institutions of China (Grant no. 14KJA560001).

\section{References}

[1] T.-S. Chang and M. P. Singh, "Mechanical model parameters for viscoelastic dampers," Journal of Engineering Mechanics, vol. 135, no. 6, pp. 581-584, 2009.

[2] R. Lewandowski and B. Chorazyczewski, "Identification of the parameters of the Kelvin-Voigt and the Maxwell fractional models, used to modeling of viscoelastic dampers," Computers \& Structures, vol. 88, no. 1-2, pp. 1-17, 2010.

[3] R.-H. Zhang and T. T. Soong, "Seismic design of viscoelastic dampers for structural applications," Journal of Structural Engineering (United States), vol. 118, no. 5, pp. 1375-1392, 1992. 
[4] K.-C. Chang and Y.-Y. Lin, "Seismic response of full-scale structure with added viscoelastic dampers," Journal of Structural Engineering, vol. 130, no. 4, pp. 600-608, 2004.

[5] J.-S. Hwang, Y.-N. Huang, S.-L. Yi, and S.-Y. Ho, "Design formulations for supplemental viscous dampers to building structures," Journal of Structural Engineering, vol. 134, no. 1, pp. 22-31, 2008.

[6] C. S. Tsai and H. H. Lee, "Applications of viscoelastic dampers to high-rise buildings," Journal of Structural Engineering, vol. 119, no. 4, pp. 1222-1233, 1993.

[7] M. L. Lai, K. C. Chang, T. T. Soong, D. S. Hao, and Y. C. Yeh, "Full-Scale viscoelastically damped steel frame," Journal of Structural Engineering, vol. 121, no. 10, pp. 1443-1447, 1995.

[8] K. C. Chang, T. T. Soong, S. T. Oh, and M. L. Lai, "Effect of ambient temperature on viscoelastically damped structure," Journal of Structural Engineering, vol. 118, no. 7, pp. 1955-1973, 1992.

[9] K. L. Shen and T. T. Soong, "Modeling of viscoelastic dampers for structural applications," Journal of Engineering Mechanics, vol. 121, no. 6, pp. 694-701, 1995.

[10] S. A. Ashour, Elastic Seismic Response of Buildings with Supplemental Damping, University of Michigan, Ann Arbor, Mich, USA, 1987.

[11] M. I. J. Chang and T. T. Soong, "Optimal controller placement in modal control of complex systems," Journal of Mathematical Analysis \& Applications, vol. 75, no. 2, pp. 340-358, 1980.

[12] A. K. Shukla and T. K. Datta, "Optimal use of viscoelastic dampers in building frames for seismic force," Journal of Structural Engineering, vol. 125, no. 4, pp. 401-409, 1999.

[13] A. S. Veletsos and J. W. Meek, "Dynamic behaviour of buildingfoundation systems," Earthquake Engineering \& Structural Dynamics, vol. 3, no. 2, pp. 121-138, 1974.

[14] J. Avilés and L. E. Pérez-Rocha, "Evaluation of interaction effects on the system period and the system damping due to foundation embedment and layer depth," Soil Dynamics and Earthquake Engineering, vol. 15, no. 1, pp. 11-27, 1996.

[15] C. Medina, J. J. Aznárez, L. A. Padrón, and O. Maeso, “Effects of soil-structure interaction on the dynamic properties and seismic response of piled structures," Soil Dynamics and Earthquake Engineering, vol. 53, pp. 160-175, 2013.

[16] E. Kausel and J. M. Roesset, Soil Structure Interaction Problems for Nuclear Containment Structures, Electric Power and the Civil Engineer, 1973.

[17] N. Makris and M. C. Constantinou, "Fractional-derivative maxwell model for viscous dampers," Journal of Structural Engineering, vol. 117, no. 9, pp. 2708-2724, 1991.

[18] L. Sun and L. Chen, "Free vibrations of a taut cable with a general viscoelastic damper modeled by fractional derivatives," Journal of Sound \& Vibration, vol. 335, pp. 19-33, 2015.

[19] M. Novak and K. Sachs, "Torsional and coupled vibrations of embedded footings," Earthquake Engineering \& Structural Dynamics, vol. 2, no. 1, pp. 11-33, 1973.

[20] G. W. Housner, "Properties of strong ground motion earthquakes," Bulletin of the Seismological Society of America, vol. 45, no. 3, pp. 197-218, 1955.

[21] C. Nuti and I. Vanzi, "Influence of earthquake spatial variability on differential soil displacements and SDF system response," Earthquake Engineering \& Structural Dynamics, vol. 34, no. 11, pp. 1353-1374, 2005.

[22] Y. Hu and X. Zhou, "Response of the elastic system to stationary and non-stationary ground motion," Earthquake Engineering of the Chinese Academy of Sciences Research Report, Science Press, Beijing, China, 1962 (Chinese).

[23] Z.-J. Liu and X. Fang, "Simulation of stationary ground motion with random functions and spectral representation," Journal of Vibration and Shock, vol. 32, no. 24, pp. 6-10, 2013 (Chinese).

[24] T. Harada and H. Tajimi, "The Japanese Society of Earthquake Engineering Committee. Seismic design and seismic dynamic analysis," Tokyo Technical Report Hall, 1989 (Japanese).

[25] J. H. Holland, Adaption in Natural and Artificial Systems, University of Michigan Press, Ann Arbor, Mich, USA, 1975.

[26] H. Furuya and R. T. Haftka, "Placing actuators on space structures by genetic algorithms and effectiveness indices," Structural Optimization, vol. 9, no. 2, pp. 69-75, 1995.

[27] O. Furuya, H. Hamazaki, and S. Fujita, "Proper placement of energy absorbing devices for reduction of wind-induced vibration caused in high-rise buildings," Journal of Wind Engineering \& Industrial Aerodynamics, vol. 74-76, pp. 931-942, 1998.

[28] Y.-J. Kim and J. Ghaboussi, "A new method of reduced order feedback control using genetic algorithms," Earthquake Engineering \& Structural Dynamics, vol. 28, no. 2, pp. 193-212, 1999. 


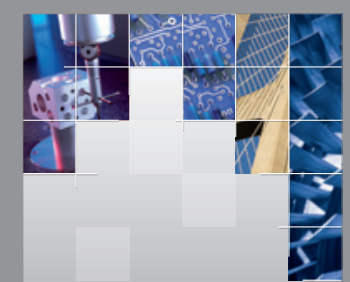

\section{Enfincering}
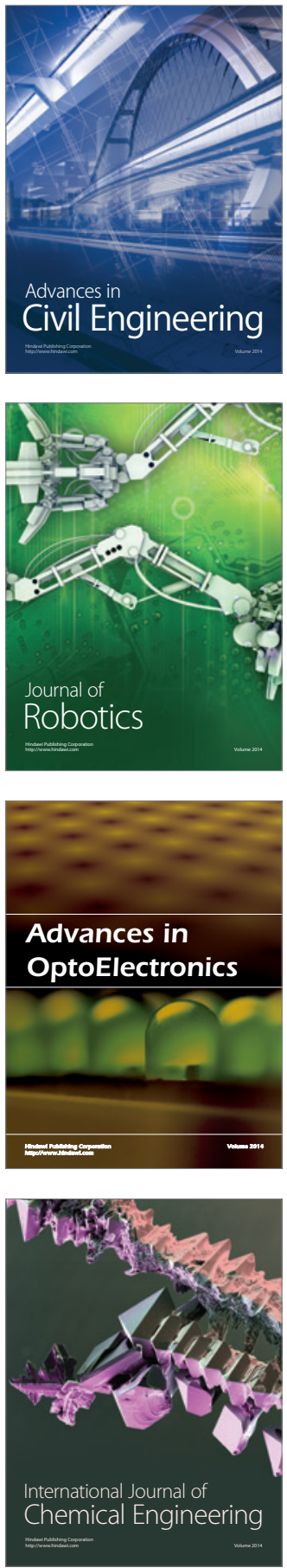

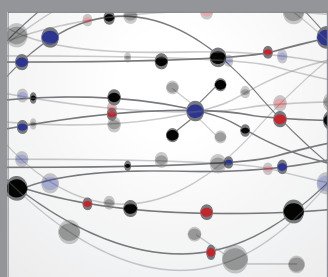

The Scientific World Journal

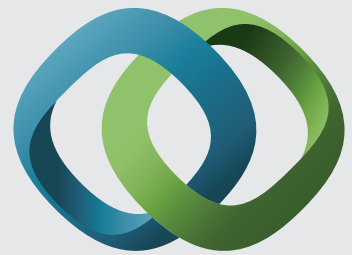

\section{Hindawi}

Submit your manuscripts at

https://www.hindawi.com
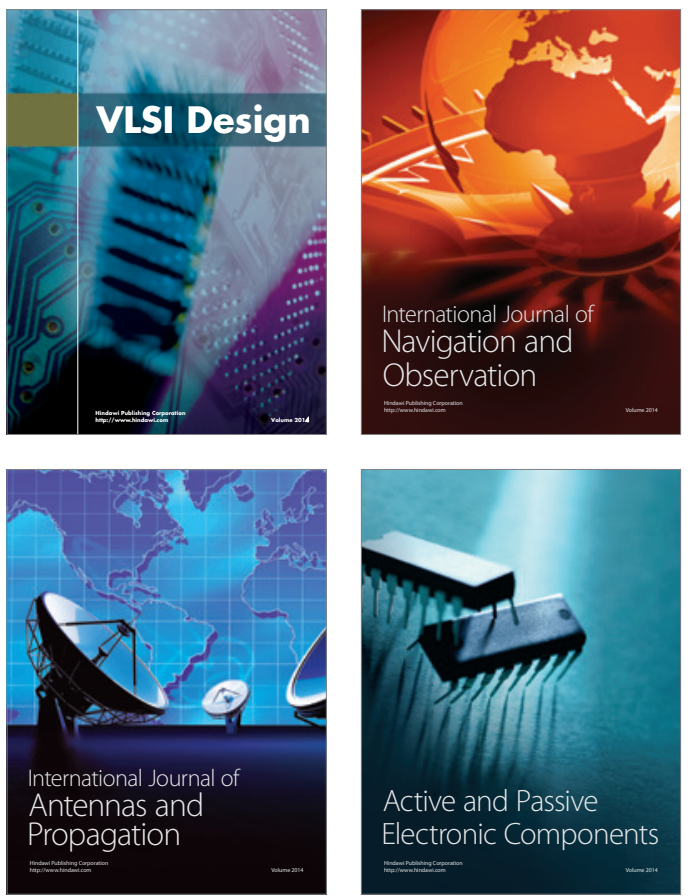
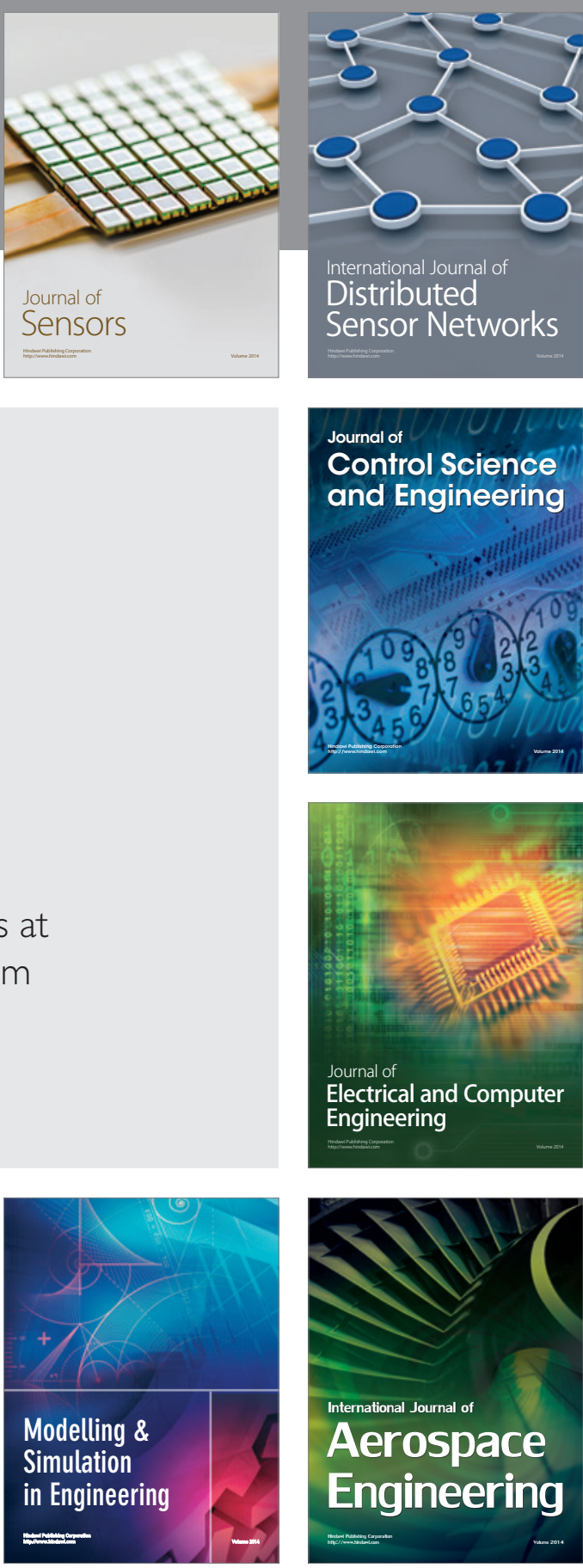

International Journal of

Distributed

Sensor Networks

$-$

Joumal of

Control Science

and Engineering
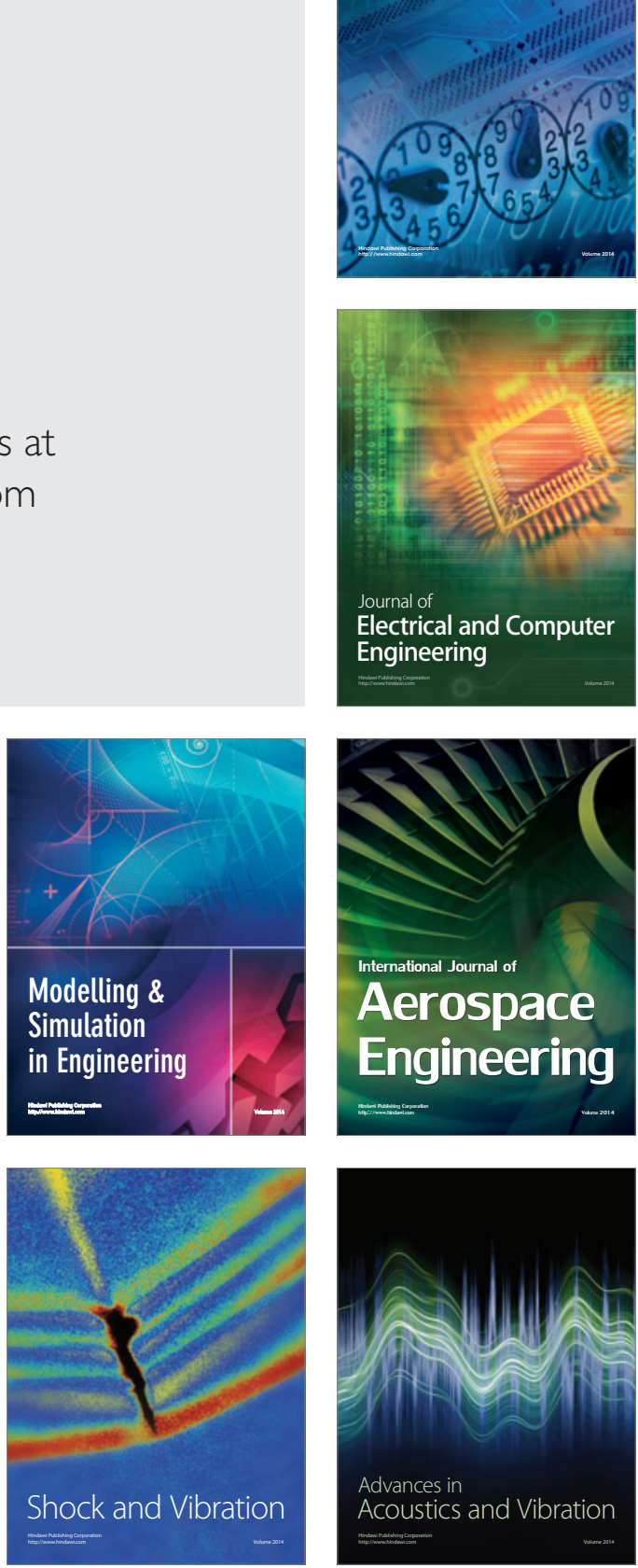